\title{
The Aggregate Dynamics of Capital Structure and Macroeconomic Risk*
}

\author{
Harjoat S. Bhamra \\ Sauder School of Business \\ University of British Columbia
}

\author{
Lars-Alexander Kuehn \\ Tepper School of Business \\ Carnegie Mellon University
}

\author{
Ilya A. Strebulaev \\ Graduate School of Business \\ Stanford University
}

This version: August 2008

\begin{abstract}
* Some of the results in this paper were previously contained in an earlier version of "The Levered Equity Risk Premium and Credit Spreads: A Unified Framework", by the same authors. We are grateful for comments from Heitor Almeida, Malcolm Baker, Ravi Bansal, Alexander David, Glen Donaldson, Darrell Duffie, Bernard Dumas, Adlai Fisher, Julian Franks, Lorenzo Garlappi, Ron Giammarino, Bob Goldstein, Dirk Hackbarth, Cam Harvey, Kris Jacobs, Tim Johnson, Dmitry Livdan, Hanno Lustig, Marcin Kacperczyk, Stephen Schaefer, Costis Skiadas, Lukas Schmid, Suresh Sundaresan, Raman Uppal, Toni Whited, Josef Zechner, and participants at the PIMS/Banff Workshop on Optimization Problems in Financial Economics, the CEPR Gerzensee European Summer Symposium on Financial Markets 2006, NFA 2006, WFA 2007, SITE 2007 Workshop on Dynamic Investment and Financing, Duke/UNC 2007 Conference on Asset Pricing, EFA 2007, and seminar participants at Boston College, Calgary, Cass Business School, Duke, HKUST, Illinois at Urbana-Champaign, London Business School, Nanyang Technological University, National University of Singapore, Penn State, Singapore Management University, Stanford, Vienna, Wharton, UBC, and UNC-Chapel Hill for helpful suggestions. We acknowledge financial support from the Social Sciences and Humanities Research Council of Canada and the Bureau of Asset Management at the Sauder School of Business. Bhamra: 2053 Main Mall, Vancouver BC, Canada V6T 1Z2; Email: harjoat.bhamra@sauder.ubc.ca; Kuehn: 5000 Forbes Avenue, Pittsburgh, PA 15213; E-mail: lakuehn@andrew.cmu.edu; Strebulaev: Graduate School of Business, Stanford University, 518 Memorial Way, Stanford, CA 94305, Email: istrebulaev@stanford. edu.
\end{abstract}




\title{
The Aggregate Dynamics of Capital Structure and Macroeconomic Risk
}

\begin{abstract}
We study the impact of time-varying macroeconomic conditions on optimal dynamic capital structure and the aggregate dynamics of firms in a cross-section. Our structural-equilibrium framework embeds a contingent-claim corporate financing model within a standard consumption-based assetpricing model. This enables us to investigate the effect of macroeconomic conditions on asset valuation and optimal corporate policies as well as study the impact of preferences on capital structure. We find that capital structure is pro-cyclical at refinancing dates when firms relever, but counter-cyclical in aggregate dynamics, consistent with empirical evidence. Financially constrained firms follow more pro-cyclical policies. Capital structure is path-dependent. Leverage accounts for most of the macroeconomic risk relevant for predicting defaults. The paper also develops a number of novel empirically testable conjectures on capital structure in a dynamic economy.
\end{abstract}

JEL Classification Numbers: E44, G12, G32, G33

Keywords: Dynamic capital structure, leverage, aggregate dynamics, cross-sectional behavior, default probability, financial constraints, macroeconomic risk, risk aversion, elasticity of intertemporal substitution 
It has been widely recognized that macroeconomic risk has a profound impact on corporate financing decisions (e.g. Hackbarth, Miao, and Morellec (2006)). Empirically, aggregate leverage in the economy has been shown to be counter-cyclical. At the same time, there is evidence suggesting that firm-level leverage is pro-cyclical. Furthermore, the impact of macroeconomic conditions on leverage depends on proxies for financial constraints such as firm size. ${ }^{1}$

In this paper we study how the optimal financial structure of firms, at both the individual and aggregate levels, is affected by time-varying macroeconomic conditions. In particular, we develop a theoretical framework where corporate debt and equity prices fluctuate with the state of the economy and dynamic corporate financial policies are determined optimally. By doing so, we are able to uncover the combination of economic forces which explain why aggregate leverage is pro-cyclical, while firm-level leverage is counter-cyclical. Our framework also allows us to explore the impact of the macroeconomic environment on financial conservatism, the effect of financial constraints, path-dependence in leverage, and the relation between current leverage and future default probabilities. We are able to explain intuitively a number of stylized facts documented by recent empirical evidence and develop novel empirical conjectures, which have not yet been tested.

To investigate all of the above issues properly, we need to account both for the optimal dynamic capital structure decisions of individual firms and decision-makers' attitudes towards macroeconomic risk, both of which affect asset prices in the economy. We do so by developing a new framework which we call a structural-equilibrium framework, since it unifies the economics behind the structural modeling of financial decisions and the equilibrium modeling of asset pricing. To understand how our structural-equilibrium model works, consider a pure structural model of capital structure (e.g. Fischer, Heinkel, and Zechner (1989), Goldstein, Ju, and Leland (2001), and Hackbarth, Miao, and Morellec (2006)), in which leverage and default decisions are derived optimally, and embed it in a consumption-based asset-pricing model with a representative agent. The advantage of such an embedding is that it endogenously links unobservable risk-neutral probabilities to observable actual probabilities via the market price of consumption risk and the agent's preferences. It allows us, therefore, to study endogenously the effect of macroeconomic risk on optimal financing decisions, since the agent prices claims based on her attitude towards the macroeconomic risks present in consumption and cash flows. In this framework, we also can explain intuitively how preferences (such as risk-aversion and the elasticity of intertemporal substitution) affect financing decisions. It also enables us to study actual default probabilities and, in particular, explore the relation between leverage and default likelihood.

\footnotetext{
${ }^{1}$ For example, see Korajczyk and Levy (2003) on aggregate and firm-level cyclicality in leverage and Gertler and Gilchrist (1993) on the cyclicality of financial decisions in the presence of financial constraints.
} 
To study intertemporal macroeconomic risk and its effect on financial structure, we utilize several intuitive features. First, the properties of both firms' earnings and consumption growth change with the state of the economy, with expected growth lower in contractions and growth volatility lower in expansions. Second, we model switches in the state of the economy via a Markov chain, a standard tool to model regime changes. ${ }^{2}$ Third, we assume that the representative agent cares about the intertemporal composition of risk. In particular, she prefers uncertainty about the future to be resolved sooner rather than later. In essence, she is averse to uncertainty about the future state of the economy. We model this by assuming that the representative agent has Epstein-Zin-Weil preferences. One important economic implication is that the average duration of bad times in the risk-neutral world is longer than in the actual world and, since the representative agent uses risk-neutral and not actual probabilities to account for risk and compute prices, the agent behaves more conservatively.

To study financing decisions, we consider a standard trade-off model of dynamic capital structure that is widely used in the literature (e.g. Fischer, Heinkel, and Zechner (1989), Goldstein, Ju, and Leland (2001), Hackbarth, Miao, and Morellec (2006), Strebulaev (2007)). In the model, firms are always on their optimal capital structure path, but, due to adjustment costs, they refinance only occasionally. Small adjustment costs can lead to long waiting times and large changes in leverage, a result consistent with the findings of Fischer, Heinkel, and Zechner (1989) and, more recently, of Welch (2004) and Leary and Roberts (2005). Firms that perform consistently well re-leverage to exploit the tax benefits of debt. Firms that perform poorly default, and ownership is transferred to debtholders.

Introducing dynamic capital structure within our structural-equilibrium framework leads to optimal financing decisions at refinancing dates when firms actively restructure their liabilities. Since firms refinance infrequently, however, most of the time their leverage drifts away from their optimal leverage chosen at a refinancing date, as observed by Strebulaev (2007). Therefore, to relate any dynamic model to empirical studies, one must use the model to produce a cross-section of leverage ratios that is structurally similar to those that could have been studied by an empiricist. Therefore, we proceed by computing cross-sectional averages of individual firms' capital structure characteristics over time and studying their aggregate dynamics.

To preview the main results our framework delivers, consider both optimal policy at refinancing dates and the aggregate cross-sectional dynamics. We find that firms behave much more conservatively when refinancing in bad times. The earnings default boundary is endogenously counter-cyclical, since equityholders' default option is lower in bad times. Target leverage is also

\footnotetext{
${ }^{2}$ See e.g. Hamilton (1989), Cecchetti, Lam, and Mark (1993), Whitelaw (2000), Hansen, Heaton, and Li (2006), Jobert and Rogers (2006), Calvet and Fisher (2007), and Calvet and Fisher (2008). The Markov chain approach to modeling intertemporal macroeconomic risk is also related to the long-risk model of Bansal and Yaron (2004).
} 
endogenously time-varying, with capital structure decisions at refinancing dates unambiguously pro-cyclical: if a firm chooses its financing at the time of a contraction, its leverage ratio is substantially lower compared to its choice of leverage at times of expansion. There are two opposing economic mechanisms which impact financial policies over the business cycle. First, for each level of book debt, equity value falls in a contraction since future dividends are expected to be low. This translates into higher leverage. Second, firms prefer to choose optimally lower debt in contractions to increase financial flexibility. This optimal choice reflects the time-varying trade-off between costly default and tax benefits to debt. The first mechanism leads to counter-cyclical optimal leverage at refinancing, while the second mechanism renders leverage pro-cyclical. We find that the second economic effect dominates for a realistic set of parameters.

While optimal leverage is pro-cyclical at the refinancing point, we find that it is actually countercyclical in aggregate dynamics for the whole cross-section. The direction of cyclicality differs between aggregate dynamics and refinancing points, since when the economy switches from good to bad states, the market value of equity drops more than the market value of debt, thus making leverage more counter-cyclical. In the aggregate, this latter effect dominates the optimal choice of debt. The difference between aggregate dynamics and refinancing points explains why it is not an easy task to study the relation between macroeconomic conditions and leverage in the data and why various studies get seemingly inconsistent results. Our result on the counter-cyclicality of the whole cross-section is consistent, for example, with Korajczyk and Levy (2003) who find leverage to be counter-cyclical for relatively unconstrained firms. On the other hand, Covas and Den Haan (2007) and Korteweg (2008) find empirically that when firms choose optimal leverage, leverage decisions are pro-cyclical, consistent with our refinancing date result.

Another set of results concerns model predictions about the levels of leverage at refinancing and in dynamics. An important empirical discussion has centered on the conservative nature of corporate debt policies relative to optimal debt levels implied by trade-off considerations. For example, Graham (2000) finds that firms too often seem to "leave money on the table" by not levering up to the optimal level. This stylized fact has often been referred to as the "low-leverage puzzle". We show that macroeconomic risk leads to substantially lower leverage at refinancing. The unconditional leverage ratio is $28 \%$, and the optimal leverage ratio at refinancing in the bad state is $22 \%$, consistent with stylized facts on the extent of debt. Based on this result, it is tempting to conclude that the low-leverage puzzle can be explained by accounting for intertemporal macroeconomic risk. In aggregate dynamics, however, leverage is substantially higher in both bad and good times, rising from $22 \%$ to $44 \%$ in contractions and from $32 \%$ to $38 \%$ in booms. There are several reasons behind the difference. Leverage dynamics are inherently asymmetric, since it is more difficult to restructure upwards than downwards and optimal leverage at refinancing points is 
relatively low. Unsuccessful firms tend to delay restructuring while successful firms restructure fairly soon. In addition, these effects are exacerbated since firms that restructure in booms also choose a relatively lower refinancing boundary. Crucially, this result demonstrates that it is misleading to try and resolve empirical puzzles, such as the low-leverage pizzle, based on refinancing point values.

Our results strongly indicate that financing decisions in dynamics exhibit substantial pathdependence, that is, they depend not only on the current state of the economy, but also on the state at the time of the previous refinancing. Firms are much more likely to default when they have refinanced in expansions, since "cheap" credit leads them to take a riskier financial position and they are thus more prone to default when macroeconomic conditions worsen. Conversely, firms are more likely to refinance in an expansion if they issued debt during contractions.

We also find that preferences have a profound effect on financial decisions. For example, higher risk aversion leads to a greater demand for precautionary savings which drives the risk-free rate lower. It also reduces risk-neutral earnings growth. Both mechanisms lead to more conservative financial policies since a lower risk-free rate raises the present value of coupon payments to debtholders and a lower risk-neutral earnings growth rate makes default more likely and tax benefits less valuable. Interestingly, while the optimal coupon is lower, the leverage ratio is almost unaffected by changes in risk aversion since greater risk aversion reduces the value of claims which pay more in good states than in bad states such as equity, counterbalancing the effect of lower debt value.

Our framework also allows us to study the differences between financially constrained and unconstrained firms based on the cost of accessing external financial markets. ${ }^{3}$ We proxy financial constraints by higher debt issuance costs in contractions, since the evidence from the credit channel literature suggests that firms which face greater financial constraints find it more difficult to tap external financial markets in bad times (Gertler and Gilchrist (1993), Gertler and Gilchrist (1994)). In the context of a dynamic financing model, Hennessy and Whited (2007) also show that small firms face larger external financial constraints. Our results show that unconstrained firms (for which debt issuance cost is independent of the macroeconomic regime) exhibit substantially less pro-cyclical behavior in the promised coupon levels and almost no cyclical pattern in leverage at refinancing dates. The leverage of constrained firms, on the other hand, exhibits a very strong pro-cyclical behavior, consistent with both empirical evidence (Korajczyk and Levy (2003)) and theoretical predictions (e.g. Kiyotaki and Moore (1997)). Interestingly, a higher degree of procyclicality exhibited by financially constrained firms is driven by decisions taken in both states. Not only do constrained firms substantially decrease their reliance on debt in bad times, but they

\footnotetext{
${ }^{3}$ Empirical studies which employ such a classification include Fazzari, Hubbard, and Petersen (1988), Carpenter, Fazzari, and Petersen (1994), Korajczyk and Levy (2003), Almeida, Campello, and Weisbach (2005), and Almeida and Campello (2007).
} 
also increase optimal debt issuance in good times in order to finance themselves while credit is relatively cheap.

We also investigate the relation between leverage and the term structure of default probabilities, motivated by the literature studying predictions of bankruptcy and default events and extensive credit risk research. We find that leverage incorporates sufficient macroeconomic information, both past and present, such that default predicting regressions do not lose much power by not controlling for macroeconomic conditions once leverage is accounted for. This lends support to using leverage as the classification benchmark in credit risk instead of credit ratings which are ambiguous and with apparently time-varying properties over the business cycle.

Finally, we also study the time-variation of financial structure. Defaults cluster, consistent with empirical evidence, and also can occur in a worsening macroeconomic environment, despite there being no change in earnings. Aggregate leverage is pro-cyclical, and capital structures across firms co-move, with the co-movement being greater in bad times.

Our paper builds on several strands of previous research. First, it inherits features of dynamic capital structure models developed in papers such as Fischer, Heinkel, and Zechner (1989), Goldstein, Ju, and Leland (2001), Hackbarth, Miao, and Morellec (2006), and Strebulaev (2007), in which the standard structural models of risky debt pricing are extended to incorporate dynamic financing behavior. Second, our structural-equilibrium framework is indebted to consumptionbased asset pricing models (Lucas (1978), Bansal and Yaron (2004)). Third, we build on previous studies relating macroeconomic conditions to capital structure, both empirically (Korajczyk and Levy (2003)) and theoretically (Hackbarth, Miao, and Morellec (2006)). Finally, we focus on exploring the aggregate dynamics of corporate financing behavior when firms refinance infrequently (Strebulaev (2007)).

We now discuss several papers with which our paper is particularly close. The contingentclaims structural model that our paper is most closely related to is Hackbarth, Miao, and Morellec (2006). They are one of the first to study theoretically the influence of macroeconomic factors on capital structure and credit spreads. There are several key differences between our frameworks and the issues that we explore. First, Hackbarth, Miao, and Morellec work solely under the riskneutral measure. In contrast, asset valuation in our economy accounts for the interaction of agents' preferences with macroeconomic risk, allowing us to endogenize the mapping between actual and risk-neutral worlds. In particular, the economy spends disproportionately more time in contractions in the risk-neutral world. This allows us to study the impact of preferences on capital structure as well as actual default probabilities and the relation between leverage and default likelihood. Second, we study financial structure both in aggregate dynamics and at refinancing dates, while Hackbarth, Miao, and Morellec focus entirely on the refinancing-date behavior. Finally, while we 
model the impact of macroeconomic factors on both cash flows and discount rates, Hackbarth, Miao, and Morellec focus on the cash flow channel by assuming that firms' earnings levels jump down in recessions.

The structural-equilibrium framework that we use is developed by Bhamra, Kuehn, and Strebulaev (2008) who study the implications of macroeconomic risk for the levered equity premium and credit spreads. We focus instead on optimal corporate finance decisions and the relation between leverage and default probability. In their study of the credit risk implications of the model, Bhamra, Kuehn, and Strebulaev also show that defaults cluster in bad times.

In order to compare the implications of our model with the data, we compute cross-sectional averages of individual firms' capital structure characteristics as in Strebulaev (2007). They key difference between our framework and Strebulaev (2007) is that we model macroeconomic conditions, together with agents' preferences, and investigate how dynamic optimal capital structure depends on both current and historical macroeconomic conditions so we can compare our theoretical results with empirical findings such as Korajczyk and Levy (2003). Contemporaneous work by Chen (2008) uses a similar theoretical framework to investigate the low-leverage and credit spread puzzles, but focuses entirely on the capital structure decisions of individual firms at refinancing points. Since, as we show, firms are almost always not at their refinancing points and empirical studies focus on aggregate data over cross-sections of firms, rather than individual firm level data, it is necessary to consider the aggregate dynamics of the model to accurately explore its empirical implications. For example, we show that while this type of model can largely account for the low-leverage puzzle by considering individual firms' optimal decisions at refinancing dates, it fails when considering aggregate leverage in dynamics.

The paper proceeds as follows. Section I describes the structural-equilibrium framework. Section II develops a model of optimal dynamic corporate financing decisions and explores implications for the valuation of corporate debt and equity. In Section III, we investigate the properties of optimal financing policies at a refinancing date. We explore the properties of our model in aggregate dynamics in Section IV. We conclude in Section V. Proofs are contained in the Appendix.

\section{Modeling Intertemporal Macroeconomic Risk}

In this section, we describe how we model time-varying macroeconomic conditions within the structural-equilibrium model. The idea behind the structural-equilibrium approach is economically intuitive: the traditional structural model of debt and capital structure is enriched by embedding it within a consumption-based asset pricing model, the workhorse model in asset pricing. In particu- 
lar, this framework allows us to understand how preferences and consumption risk impact corporate financing decisions.

Our structural-equilibrium model closely follows that of Bhamra, Kuehn, and Strebulaev (2008). We now describe how we model individual firm earnings growth rates, aggregate consumption, and macroeconomic conditions.

\section{I.A Firm Earnings, Aggregate Consumption, and Time-Varying Macroeconomic Conditions}

The are $N$ firms in the economy. A portion of each firm's output consists of a cash flow or earnings stream, which is distributed to stakeholders. The remainder of a firm's output is paid as wages to workers. We assume that the cash flow level of firm $n, X_{n}$, is given by

$$
\frac{d X_{n, t}}{X_{n, t}}=\theta_{t} d t+\sigma_{X}^{i d} d B_{X, n, t}^{i d}+\sigma_{X, t}^{s} d B_{X, t}^{s}
$$

where $\theta_{n}$ is the expected earnings growth rate of firm $n$, and $\sigma_{X}^{i d}$ and $\sigma_{X}^{s}$ are, respectively, the idiosyncratic and systematic volatilities of the firm's earnings growth rate. Total risk, $\sigma_{X}$, is given

by $\sigma_{X, t}=\sqrt{\left(\sigma_{X}^{i d}\right)^{2}+\left(\sigma_{X, t}^{s}\right)^{2}}$. The standard Brownian motion $B_{X, t}^{s}$ is the systematic shock to the firm's earnings growth, which is correlated with aggregate consumption growth:

$$
d B_{X, t}^{s} d B_{C, t}=\rho_{X C} d t
$$

where $\rho_{X C}$ is the correlation coefficient. The standard Brownian motion $B_{X, n, t}^{i d}$ is the idiosyncratic shock to firm $n$ 's earnings, which is correlated with neither $B_{X, t}^{s}$ nor $B_{C, t}$. Naturally, idiosyncratic shocks are uncorrelated across firms.

Aggregate consumption, $C$ equals the aggregate output of all firms in the economy. Hence,

$$
C=\sum_{n=1}^{N} X_{n}+W
$$

where $W$ is aggregate wages. We assume aggregate consumption, $C$, is given by

$$
\frac{d C_{t}}{C_{t}}=g_{t} d t+\sigma_{C_{t}} d B_{C, t}
$$

where $g$ is expected consumption growth, $\sigma_{C}$ is consumption growth volatility, and $B_{C, t}$ is a standard Brownian motion. Thus, aggregate wages are the difference between aggregate consumption and aggregate earnings. This way of modeling aggregate consumption and wage processes is standard in asset pricing literature such as Kandel and Stambaugh (1991), Cecchetti, Lam, and Mark (1993), Campbell and Cochrane (1999), and Bansal and Yaron (2004). 
To account for variation in macroeconomic conditions, we assume that the first and second moments of macroeconomic growth rates are stochastic. Intuitively, expected growth is lower in contractions while volatility is higher. Therefore, we assume that the conditional expected growth rate of consumption, $g_{t}$, can take two values, $g_{1}$ and $g_{2}$, and, similarly for $\theta_{t}, \sigma_{C, t}$, and $\sigma_{X, t}^{s} \cdot{ }^{4}$ We assume state 1 is the bad state and state 2 is the good state and since the first (second) moments of fundamental growth rates are pro-cyclical (counter-cyclical), we assume that $g_{1}<g_{2}, \theta_{1}<\theta_{2}$, $\sigma_{C, 1}>\sigma_{C, 2}$, and $\sigma_{X, 1}^{s}>\sigma_{X, 2}^{s}$.

The state changes according to a 2 -state Markov chain, defined by $\lambda_{\nu_{t}}, \nu_{t} \in\{1,2\}$, which is the probability per unit time of the economy leaving state $\nu_{t}$. The Markov chain gives rise to uncertainty about the future moments of consumption growth. ${ }^{5}$ This intertemporal consumption risk impacts asset prices and hence corporate financing decisions only if the representative agent cares about the intertemporal distribution of risk. Therefore, our choice of preferences for the representative agent is crucial.

If we were to choose standard power utility, then the pricing kernel would be given by

$$
\pi_{t}=e^{-\beta t} C_{t}^{-\gamma}
$$

where $\beta$ is the rate of time preference and $\gamma$ is relative risk aversion (RRA). The power utility agent is indifferent to whether uncertainty about the future moments of consumption growth is resolved sooner or later. Thus, instantaneous changes in the drift and volatility of consumption growth do not affect the current level of the pricing kernel and intertemporal consumption risk is not priced. To ensure that the agent does care about the timing of the resolution of intertemporal risk, we assume the representative agent has the continuous-time analog of Epstein-Zin-Weil preferences. ${ }^{6}$ Using preferences of this type has recently become standard in asset pricing, e.g, the long-run risk literature initiated by Bansal and Yaron (2004).

\footnotetext{
${ }^{4}$ To ensure idiosyncratic earnings volatility, $\sigma_{X}^{i d}$, is truly idiosyncratic, we assume it is constant and thus independent of the state of the economy. We also assume that the correlation coefficient, $\rho_{X C}$, is constant.

${ }^{5}$ The extension to more than two states does not provide any further economic intuition and is straightforward. To model the first and second moments of fundamental growth rates, we could use any stochastic process with an underlying probability distribution that is both non-stationary and converges to a stationary distribution. Employing a Markov chain has two advantages. First, it allows us to ensure that bad states of the economy are of shorter mean duration than good states. The mean duration of state $i$ is $\frac{1}{\lambda_{i}}$ and we can assume that $\frac{1}{\lambda_{1}}<\frac{1}{\lambda_{2}}$. This captures the fact that recessions are shorter than booms. Using an Ornstein-Uhlenbeck process (the continuous time analog of the AR(1) process used in Bansal and Yaron (2004)) or a Cox-Ingersoll Ross process, which both have symmetric transition probabilities, would force the duration of good and bad states to be equal. Second, we can derive asset prices exactly in closed-form rather than using the log-linear approximation of Campbell and Shiller (1988).

${ }^{6}$ The continuous-time version of the recursive preferences introduced by Epstein and Zin (1989) and Weil (1990) is known as stochastic differential utility, and is derived in Duffie and Epstein (1992). Schroder and Skiadas (1999) provide a proof of existence and uniqueness.
} 
Consequently, the representative agent's pricing kernel at time- $t, \pi_{t}$, is given by (see Appendix B of Bhamra, Kuehn, and Strebulaev (2008) for the derivation)

$$
\pi_{t}=\left(\beta e^{-\beta t}\right)^{\frac{1-\gamma}{1-\frac{1}{\psi}}} C_{t}^{-\gamma}\left(p_{C, t} e^{\int_{0}^{t} p_{C, s}^{-1} d s}\right)^{-\frac{\gamma-\frac{1}{\psi}}{1-\frac{1}{\psi}}}
$$

where $\psi$ is the elasticity of intertemporal substitution under certainty (EIS) and $p_{C}$ is the priceconsumption ratio. The EIS measures how tolerant the agent is of a non-smooth consumption path over time. Intuitively, the EIS impacts the agent's preferences over time, while RRA impacts her preferences over states. When $\gamma=1 / \psi$, the pricing kernel in (5) reduces to (4) for pricing purposes.

The Epstein-Zin-Weil agent cares whether news about consumption growth and hence future consumption is bad or good. Her pricing kernel, unlike that of the power-utility agent, depends on the value of the claim to aggregate consumption per unit consumption, i.e. the price-consumption ratio, $p_{C}$. In particular, if $\gamma>1 / \psi$, the agent prefers intertemporal risk to be resolved sooner rather than later, an economically plausible scenario we assume throughout the paper. Kreps and Porteus (1978, p. 186) explain the underlying intuition as follows: "If ... the coin flip determines your income for the next two years, you probably prefer to have the coin flipped now [instead of later] ...". Consequently, bad news about consumption growth increases the pricing kernel.

The intertemporal distribution of risk is affected not only by whether news about consumption growth is good or bad, but also by the speed at which this news arrives. The rate of news arrival is governed by the rate at which the distribution for the state of the economy converges to its steady state. The convergence rate is given by $p=\lambda_{1}+\lambda_{2}$. A smaller $p$ means news arrives more slowly and thus there is more intertemporal risk. The long-run distribution is then given by $\left(f_{1}, f_{2}\right)=\left(\frac{\lambda_{2}}{p}, \frac{\lambda_{1}}{p}\right)$, where $f_{i}$ is the long-run probability of being in state $i$.

Importantly, the switching probabilities per unit time, $\lambda_{\nu_{t}}, \nu_{t} \in\{1,2\}$, are not directly relevant for valuing corporate securities. Instead, we must account for risk by using the risk-neutral switching probabilities per unit time, which we denote by $\widehat{\lambda}_{\nu_{t}}$. The following proposition relates the risk-neutral to the actual switching probabilities (per unit time) via the pricing kernel.

Proposition 1 The risk-neutral switching probabilities per unit time are related to the actual switching probabilities per unit time by the risk-distortion factor, $\omega$,

$$
\begin{aligned}
& \widehat{\lambda}_{1}=\lambda_{1} \omega^{-1}, \\
& \widehat{\lambda}_{2}=\lambda_{2} \omega,
\end{aligned}
$$


where $\omega$ measures the size of the jump in the pricing kernel when the economy shifts from state 2 to state 1 , i.e. ${ }^{7}$

$$
\omega=\left.\frac{\pi_{t}}{\pi_{t-}}\right|_{\nu_{t-}=2, \nu_{t}=1} .
$$

The size of the risk-distortion factor depends on the representative agent's preferences for resolving intertemporal risk: $\omega>1(\omega<1)$ if $\gamma>1 / \psi(\gamma<1 / \psi)$, and $\omega=1$ if $\gamma=1 / \psi$.

The risk-neutral switching probabilities are obtained from the actual probabilities by 'distorting' them via the risk distortion factor, $\omega$, which is defined in (8) as the change in the pricing kernel when the state of the economy changes from good to bad. The price of risk associated with a change in the state of the economy from good to bad is hence given by $\omega-1$. Importantly, the risk-neutral probability per unit time of switching from the good state to the bad state is higher than the actual probability, i.e. $\widehat{\lambda}_{2}>\lambda_{2}$. Conversely, the risk-neutral probability per unit time of switching from the bad state to the good state is lower than the actual probability, i.e. $\widehat{\lambda}_{1}<\lambda_{1}$. In other words, securities are priced as if the bad state lasts longer and the good state finishes earlier when $\gamma>1 / \psi$.

In the next section, we explain how, given asset prices, the optimal dynamic corporate financing behavior of individual firms can be derived.

\section{Dynamic Financing Decisions and Valuation}

In this section, we describe corporate financing decisions in our framework, discuss their dynamic nature, and derive the values of corporate securities.

\section{II.A Unlevered Asset Value}

To understand how assets are priced in this economy, consider the value of unlevered assets. The firm's state-conditional asset value, also called liquidation or abandonment value and denoted by $A_{\nu_{t}}$, is the after-tax value of the unlevered firm's future earnings, $X$, when the current state is $\nu_{t}$ :

$$
A_{\nu_{t}}=(1-\eta) X_{t} E_{t}\left[\int_{t}^{\infty} \frac{\pi_{s} X_{s}}{\pi_{t} X_{t}} d s \mid \nu_{t}\right], \text { for } \nu_{t} \in\{1,2\}
$$

where corporate income is taxed at the rate $\eta .{ }^{8}$ The liquidation value in (9) is a function of the current earnings level and is time-independent, $A_{\nu_{t}}=A_{\nu_{t}}\left(X_{t}\right)$. The next proposition derives the value of $A_{\nu_{t}}$ in terms of fundamentals of the economy.

\footnotetext{
${ }^{7}$ To distinguish between the state of the economy before and after the jump, denote the time just before the jump occurs by $t$-, and the time at which the jump occurs by $t$. We give precise definitions of the left and right limits, $\nu_{t-}$ and $\nu_{t}$, respectively, in Equations (A1) and (A2) in Appendix A.

${ }^{8}$ We assume this particular tax code for simplicity. Introducing other taxes (such as partial loss offsets in financial distress and personal income taxes) changes neither the structure of the model nor economic intuition.
} 
Proposition 2 The liquidation value in state $\nu_{t} \in\{1,2\}$ is given by

$$
A_{\nu_{t}}\left(X_{t}\right)=\frac{(1-\eta) X_{t}}{r_{A, \nu_{t}}}
$$

where

$$
r_{A, \nu_{t}}=\bar{\mu}_{\nu_{t}}-\theta_{\nu_{t}}+\frac{\left(\bar{\mu}_{j}-\theta_{j}\right)-\left(\bar{\mu}_{\nu_{t}}-\theta_{\nu_{t}}\right)}{\widehat{p}+\bar{\mu}_{j}-\theta_{j}} \widehat{f}_{j}, j \neq \nu_{t},
$$

and

$$
\bar{\mu}_{\nu_{t}}=r_{\nu_{t}}+\gamma \rho_{X C} \sigma_{X, \nu_{t}}^{s} \sigma_{C, \nu_{t}}
$$

is the discount rate in the standard Gordon growth model.

Expressing unlevered asset value in this way allows us to compare it to similar expressions in a standard single-state economy. To see the intuition, suppose the economy is currently in state $i$. Then, the risk-neutral probability of the economy switching into a different state during a small time interval $\Delta t$ is $\widehat{\lambda}_{i} \Delta t$ and the risk-neutral probability of not switching is $1-\widehat{\lambda}_{i} \Delta t$. We can therefore write the unlevered firm value in state $i$ as

$$
A_{i}=(1-\eta) X \Delta t+e^{-\left(\bar{\mu}_{i}-\theta_{i}\right) \Delta t}\left[\left(1-\widehat{\lambda}_{i} \Delta t\right) A_{i}+\widehat{\lambda}_{i} \Delta t A_{j}\right], i, j \in\{1,2\}, j \neq i .
$$

The first term in (13) is the after-tax cash flow received in the next instant and the second term is the discounted continuation value. The continuation value is the average of $A_{i}$ and $A_{j}$, weighted by the risk-neutral probabilities of being in these states a small instant $\Delta t$ from now. For example, with risk-neutral probability $\widehat{\lambda}_{i} \Delta t$ the economy switches to state $j \neq i$ and the abandonment value jumps to $A_{j}$. The continuation value is discounted back at a rate reflecting the discount rate $\bar{\mu}_{i}$ and the expected earnings growth rate over that instant which is $\theta_{i}$.

To understand the intuition behind (11), note that if the economy stays in state $i$ forever, then (11) reduces to the standard expression $r_{A, i}=\bar{\mu}_{i}-\theta_{i}$. If the economy is, say, in state 1 (contraction), then (11) is obtained by adjusting $\bar{\mu}_{1}-\theta_{1}$ downwards by $\frac{\left(\bar{\mu}_{2}-\theta_{2}\right)-\left(\bar{\mu}_{1}-\theta_{1}\right)}{\widehat{p}+\bar{\mu}_{2}-\theta_{2}} \widehat{p} \widehat{f}_{2}<0$, to account for time spent in state 2 (expansion) at future times. The magnitude of the adjustment increases with the growth rate in the boom state, $\theta_{2}$, and the risk-neutral probability per unit time of switching into state $2, \widehat{\lambda}_{1}=\widehat{p} \widehat{f}_{2}$. Note that as news arrival under the risk-neutral measure speeds up (i.e., $\widehat{p}$ increases), the adjustment approaches $\left[\left(\bar{\mu}_{2}-\theta_{2}\right)-\left(\bar{\mu}_{1}-\theta_{1}\right)\right] \widehat{f}_{2}$ and $r_{A, 1}$ approaches $\left(\bar{\mu}_{1}-\theta_{1}\right) \widehat{f}_{1}+\left(\bar{\mu}_{2}-\theta_{2}\right) \widehat{f}_{2}$, which is the long-run risk-neutral mean of the difference between the discount rate and the expected earnings growth rate. 


\section{II.B Dynamic Financing Decisions}

We follow standard EBIT-based capital structure models (see e.g. Goldstein, Ju, and Leland (2001)) and assume the earnings of a firm, $X$, are split between a coupon, $c$, promised to debtholders in perpetuity and a dividend, $X-c$, paid to equityholders. The after-tax distribution to equityholders is therefore $(1-\eta)(X-c)$. Equityholders of each individual firm make three types of corporate financing decisions: (i) they have the right to default at the time of their choice; (ii) they decide when to refinance the firm's debt obligations; and (iii) they decide on the amount of debt to be issued at each refinancing.

As is well-known, equityholders exercise their default option if earnings drop below a certain earnings level, called the default boundary. As we discuss in Section II.D, the default boundary in our framework is endogenously state-dependent. For now we assume that default occurs in state $\nu_{t}$ when $X$ reaches the default boundary, $X_{D, \nu_{t}}$, for the first time. Upon default, bondholders recover a proportion of the firm's assets in lieu of coupons, i.e. a fraction $\alpha_{\nu_{t}}$ of the after-tax present value of the firm's earnings.

At date 0 , equityholders choose how much debt to issue, by selecting the coupon, $c_{\nu_{0}}$, which depends on the state of the economy at that date. At later times, equityholders can choose to restructure their existing debt obligations. In common with the literature we assume that refinancings are leverage increasing transactions since empirical evidence demonstrates that reducing leverage in distress is much costlier. Firms also prefer to refinance infrequently since each refinancing is costly (Fischer, Heinkel, and Zechner (1989)). At each refinancing, equityholders choose a new coupon to maximize their value. Intuitively, refinancing boundaries depend on the current state of the economy and the most recent coupon. This introduces path-dependence of capital structure in the sense that historical macroeconomic conditions affect current capital structure. We now explain how we implement this in an economy where the state changes stochastically and what exactly happens at each refinancing date.

It is convenient to divide time into periods. A period is the time interval between two consecutive refinancing dates. It is convenient to denote the beginnings of such periods by date 0 . Within each period, default occurs when a firm's cash flow level reaches a lower boundary, $X_{D, \nu_{0} \nu_{D}}$, where $\nu_{0}$ was the state at the most recent refinancing date and $\nu_{D}$ is the state of the economy at default. Our notation emphasizes that default decisions depend on both the initial state and the current state. Since our economy has two states, there are four default boundaries for each coupon value:

$$
\left\{X_{D, 11}, X_{D, 12}, X_{D, 21}, X_{D, 22}\right\}
$$

Refinancing occurs when earnings reach an upper boundary, $X_{U, \nu_{0} \nu_{U}}$, which again depends on $\nu_{0}$ and the state of the economy at refinancing, $\nu_{U}$. Hence, there are four possible refinancing boundaries 
for each coupon value:

$$
\left\{X_{U, 11}, X_{U, 12}, X_{U, 21}, X_{U, 22}\right\}
$$

In the dynamic capital structure model specification that we consider below, a homogeneity property holds, which is an extension of the homogeneity property in the single-state model (see e.g. Fischer, Heinkel, and Zechner (1989) and Goldstein, Ju, and Leland (2001)) to the case of regime switching. Denote $\xi_{\nu_{U}}\left(c_{\nu_{0}}\right)$ and $\varsigma_{\nu_{D}}\left(c_{\nu_{0}}\right)$ to be scaling factors that depend on the state at refinancing and default, respectively, and the coupon chosen at the beginning of the refinancing period. These scaling factors are defined as:

$$
\xi_{\nu_{U}}\left(c_{\nu_{0}}\right)=\frac{X_{U, \nu_{0} \nu_{U}}\left(c_{\nu_{0}}\right)}{X_{0}} \text { and } \varsigma_{\nu_{D}}\left(c_{\nu_{0}}\right)=\frac{X_{D, \nu_{0} \nu_{D}}\left(c_{\nu_{0}}\right)}{X_{0}}
$$

The homogeneity property holds when: (i) $\xi$ and $\varsigma$ above are time-invariant and level-invariant quantities; and (ii) the following conditions are satisfied:

$$
\begin{aligned}
& \xi_{i}\left(c_{i}\right)=\xi_{i}\left(c_{j}\right) \frac{c_{i}}{c_{j}}, i, j=1,2 ; \\
& \varsigma_{i}\left(c_{i}\right)=\varsigma_{i}\left(c_{j}\right) \frac{c_{i}}{c_{j}}, i, j=1,2 .
\end{aligned}
$$

Condition (i) above is the homogeneity property of Fischer, Heinkel, and Zechner (1989). Condition (ii) allows us to map optimal decisions from one state into another state.

Using the homogeneity property, we can relate optimal coupons and boundaries between two consecutive periods. In particular,

$$
c_{i}^{\prime}\left(c_{i}\right)=\xi_{i}\left(c_{i}\right) c_{i} \text { and } c_{i}^{\prime}\left(c_{j}\right)=\xi_{i}\left(c_{j}\right) c_{i}
$$

and

$$
\frac{X_{U, i \nu_{U}}\left(c_{\nu_{i}}\right)}{c_{i} X_{0}}=\frac{X_{U, j \nu_{U}}^{\prime}\left(c_{\nu_{j}}^{\prime}\right)}{c_{j} X_{0}^{\prime}}
$$

where' denotes a variable for a new period.

Given this structure, we now proceed to value corporate securities in this economy.

\section{II.C Corporate Debt and Equity Valuation}

To ensure our expressions for corporate debt and equity values are as simple and intuitive as possible, we write them in terms of the prices of a set of fundamental Arrow-Debreu default and refinancing claims, and so we start by defining these securities. The Arrow-Debreu default claim, denoted by $q_{D, \nu_{t} \nu_{D}}\left(X_{t}, \nu_{0}\right)$, is the time- $t$ value of a unit of consumption paid upon default if the 
current state is $\nu_{t}$ and the state at the moment of default is $\nu_{D}$, provided that refinancing has not already taken place. In other words, if the time- $t$ state is $\nu_{t}$ and earnings hit the boundary $X_{D, \nu_{D}}$ from above for the first time in state $\nu_{D}$, one unit of consumption is paid that instant. Importantly, since the claim's value is a function of the optimal default and refinancing thresholds, its value depends on the state of the economy at the most recent refinancing, $\nu_{0}$, as the notation signifies. In the same fashion, the Arrow-Debreu refinancing claim $q_{U, \nu_{t} \nu_{U}}\left(X_{t}, \nu_{0}\right)$ pays out a unit of consumption at refinancing if refinancing occurs in state $\nu_{U}$ and the current state is $\nu_{t}$ and, similarly to default claims, it depends on the state of the economy at the most recent refinancing.

Since each Arrow-Debreu default and refinancing claim is effectively a digital put, their values can be derived by solving a system of ordinary differential equations, which is derived from the following basic asset pricing equations

$$
E_{t}^{\mathbb{Q}}\left[d q_{D, \nu_{t} \nu_{D}}\left(X_{t}, \nu_{0}\right)-r_{\nu_{t}} q_{D, \nu_{t} \nu_{D}}\left(X_{t}, \nu_{0}\right) d t\right]=0, \nu_{t}, \nu_{D} \in\{1,2\}
$$

and

$$
E_{t}^{\mathbb{Q}}\left[d q_{U, \nu_{t} \nu_{U}}\left(X_{t}, \nu_{0}\right)-r_{\nu_{t}} q_{U, \nu_{t} \nu_{U}}\left(X_{t}, \nu_{0}\right) d t\right]=0, \nu_{t}, \nu_{U} \in\{1,2\},
$$

where $\mathbb{Q}$ is the risk-neutral measure. Intuitively, the above conditions hold because of the noarbitrage restriction. Closed-form expressions for $q_{U}$ and $q_{D}$ are given in Proposition B1 of Appendix B.

To value corporate debt, denote by $B_{\nu_{t}}\left(X_{t}, c_{\nu_{0}}, \nu_{0}\right)$ the value of debt where $\nu_{0}$ is the state at the previous refinancing, $c_{\nu_{0}}$ is the current coupon, and $\nu_{t}$ is the current state. We can write the value of debt in terms of fundamental Arrow-Debreu securities as

$$
\begin{array}{r}
B_{\nu_{t}}\left(X_{t}, c_{\nu_{0}}, \nu_{0}\right)=\frac{c_{\nu_{0}}}{r_{P, \nu_{t}}}+\sum_{\nu_{D}=1}^{2} q_{D, \nu_{t} \nu_{D}}\left(X_{t}, \nu_{0}\right)\left(\alpha_{\nu_{D}} A_{\nu_{D}}\left(X_{D, \nu_{0} \nu_{D}}\right)-\frac{c_{\nu_{0}}}{r_{P, \nu_{D}}}\right) \\
+\sum_{\nu_{U}=1}^{2} q_{U, \nu_{t} \nu_{U}}\left(X_{t}, \nu_{0}\right)\left(R_{\nu_{0} \nu_{U}}-\frac{c_{\nu_{0}}}{r_{P, \nu_{U}}}\right),
\end{array}
$$

where

$$
r_{P, \nu_{t}}=r_{\nu_{t}}+\frac{r_{j}-r_{\nu_{t}}}{\widehat{p}+r_{j}} \widehat{p}_{j}, j \neq \nu_{t}
$$

In (21), $c_{\nu_{0}} / r_{P, \nu_{t}}$ is the value of a risk-free consol bond paying coupon $c_{\nu_{0}}$ and $r_{P, \nu_{t}}$ is the perpetual risk-free interest rate in state $\nu_{t} .{ }^{9}$ The second term in the first line is the recovery value of the firm received by bondholders if default takes place less the value of the coupon payments lost

\footnotetext{
${ }^{9}$ Note that $r_{P, \nu_{t}}$ is not equal to the risk-free rate in state $\nu_{t}, r_{\nu_{t}}$, because the risk-free rate is expected to change in the future whenever the state of the economy switches. Equation (22) can be obtained from (11) by replacing the Gordon growth model discount rate, $\bar{\mu}_{\nu_{t}}$, with the risk-free rate, $r_{\nu_{t}}$, and setting the expected growth rate of earnings, $\theta_{\nu_{t}}$, equal to zero.
} 
due to default, multiplied by an Arrow-Debreu default claim, $q_{D}$. The second line is the payment made to bondholders at refinancing, denoted by $R_{\nu_{0} \nu_{U}}$, less the value of the coupons lost, multiplied by an Arrow-Debreu refinancing claim, $q_{U}$.

Observe that (21) holds for a general refinancing payment, $R_{\nu_{0} \nu_{U}}$. The exact form of the refinancing payment depends on the bond indenture provisions such as callability and seniority. For example, if debt is callable at its book value, then $R_{\nu_{0} \nu_{U}}$ is the original par value of debt. If debt is non-callable, $R_{\nu_{0} \nu_{U}}$ is the continuation value of debt. For simplicity, we assume that debt is non-callable and issued pari passu, i.e. all outstanding debt issues have equal seniority. Dilution is on a per-coupon basis, so that if the coupon at the previous refinancing is $c_{\nu_{0}}$, and at refinancing the new coupon is $c_{\nu_{U}}\left(c_{\nu_{0}}\right)$, then the continuation value of the original debt issued at the previous refinancing date is ${ }^{10}$

$$
R_{\nu_{0}, \nu_{U}}=\frac{c_{\nu_{0}}}{c_{\nu_{U}}\left(c_{\nu_{0}}\right)} B_{\nu_{U}}\left(X_{U, \nu_{0}, \nu_{t}}, c_{\nu_{U}}\left(c_{\nu_{0}}\right), \nu_{U}\right)
$$

where $B_{\nu_{U}}\left(X_{U, \nu_{0}, \nu_{t}}, c_{\nu_{U}}\left(c_{\nu_{0}}\right), \nu_{U}\right)$ is the bond value at the time of refinancing.

Based on the above structure of the refinancing payment, we can derive bond prices at refinancing dates and hence at all dates, as shown in the following proposition.

Proposition 3 Suppose that the refinancing payment $R$ is given by (23). Then the homogeneity property ((14) - (16)) holds, and the date-t debt value is given by

$$
B_{\nu_{t}}\left(X_{t}, c_{\nu_{0}}, \nu_{0}\right)=\frac{c_{\nu_{0}}}{r_{P, \nu_{t}}}\left(1-\sum_{\nu_{D}=1}^{2} q_{D, \nu_{t} \nu_{D}}\left(X_{t}, X_{D, \nu_{0} \nu_{D}}\right) l_{D, \nu_{t} \nu_{D}}-\sum_{\nu_{D}=1}^{2} q_{U, \nu_{t} \nu_{D}}\left(X_{t}, X_{U, \nu_{0} \nu_{D}}\right) l_{U, \nu_{t} \nu_{D}}\right)
$$

where loss ratios conditional on default and refinancing are given, respectively, by

$$
l_{D, \nu_{t} \nu_{D}}=\frac{\frac{c_{\nu_{0}}}{r_{P, \nu_{D}}}-\alpha_{\nu_{D}} A_{\nu_{D}}\left(X_{D, \nu_{0} \nu_{D}}\right)}{\frac{c_{\nu_{0}}}{r_{P, \nu_{t}}}} \text { and } l_{U, \nu_{t} \nu_{U}}=\frac{\frac{c_{\nu_{0}}}{r_{P, \nu_{U}}}-B_{\nu_{U}}\left(X_{U, \nu_{0} \nu_{U}}, c_{\nu_{U}}, \nu_{U}\right)}{\frac{c_{\nu_{0}}}{r_{P, \nu_{t}}}}
$$

and the bond value at refinancing, $B_{\nu_{U}}\left(X_{U, \nu_{0} \nu_{U}}, c_{\nu_{U}}, \nu_{U}\right)$, is given by (B15) in Appendix B.

To value equity, we must distinguish between equity value just after refinancing, $S$, and equity value just prior to refinancing, $E$. The value of equity just after refinancing is

$$
S_{\nu_{t}}\left(X_{t}, c_{\nu_{0}}, \nu_{0}\right)=\operatorname{Div}_{\nu_{t}}\left(X_{t}, c_{\nu_{0}}, \nu_{0}\right)+\sum_{\nu_{U}=1}^{2} q_{U, \nu_{t} \nu_{U}}\left(X_{t}, X_{\nu_{0} \nu_{U}}\right) E_{\nu_{0} \nu_{U}}
$$

\footnotetext{
${ }^{10}$ Other definitions of $R$ can be incorporated into the model, but with a loss of the homogeneity property.
} 
where $D i v_{\nu_{t}}$ is the present value of dividends paid to equityholders during the current refinancing period when the current state is $\nu_{t}$, and can be written as

$$
\begin{aligned}
\operatorname{Div}_{\nu_{t}}\left(X_{t}, c_{\nu_{0}}, \nu_{0}\right)= & A_{\nu_{t}}\left(X_{t}\right)-(1-\eta) \frac{c_{\nu_{0}}}{r_{P, \nu_{t}}}+\sum_{\nu_{D}=1}^{2} q_{D, \nu_{t} \nu_{D}}\left(X_{t}, X_{D, \nu_{0} \nu_{D}}\right)\left[(1-\eta) \frac{c_{\nu_{0}}}{r_{P, \nu_{D}}}-A_{\nu_{D}}\left(X_{D, \nu_{0} \nu_{D}}\right)\right] \\
& +\sum_{\nu_{U}=1}^{2} q_{U, \nu_{t} \nu_{U}}\left(X_{t}, X_{U, \nu_{0} \nu_{U}}\right)\left[(1-\eta) \frac{c_{\nu_{0}}}{r_{P, \nu_{U}}}-A_{\nu_{U}}\left(X_{U, \nu_{0} \nu_{U}}\right)\right] .
\end{aligned}
$$

The second term in (27) shows that, if default occurs, equityholders are no longer liable to pay coupons but lose the right to future dividends. The third term shows a similar adjustment for the effect of refinancing.

The second term in (26) is present because, if refinancing occurs, equityholders derive value from cash flow payments made after refinancing. In the case of the pari passu covenant assumed above for the valuation of debt, equity value just prior to refinancing can be written as

$$
\begin{aligned}
E_{\nu_{0} \nu_{U}}\left(X_{U, \nu_{0} \nu_{U}}\right)= & \left(1-\iota_{\nu_{U}}\right) B_{\nu_{U}}\left(X_{U, \nu_{0} \nu_{U}}, c_{\nu_{U}}\left(c_{\nu_{0}}\right), \nu_{U}\right)-R_{\nu_{0} \nu_{U}}\left(X_{U, \nu_{0} \nu_{U}}, c_{\nu_{0}}, c_{\nu_{U}}\left(c_{\nu_{0}}\right), \nu_{U}\right) \\
& +S_{\nu_{U}}\left(X_{U, \nu_{0} \nu_{U}}, c_{\nu_{U}}\left(c_{\nu_{0}}\right), \nu_{U}\right),
\end{aligned}
$$

where a proportion $\iota_{\nu_{U}}$ of the newly issued bond's value is lost due to refinancing costs, when refinancing takes place in state $\nu_{U}$.

Given the above expression for equity value just prior to refinancing, we can derive equity values at refinancing dates and hence at all dates, as shown in the following proposition.

Proposition 4 Suppose that the bond refinancing payment, $R$, is given by (23), so that the homogeneity property ((14) - (16)) holds and the value of equity just before refinancing is given by (28). Then equity values are given by

$$
\begin{aligned}
S_{\nu_{t}}\left(X_{t}, c_{\nu_{0}}, \nu_{0}\right)= & \operatorname{Div}_{\nu_{t}}\left(X_{t}, c_{\nu_{0}}, \nu_{0}\right) \\
& +\sum_{\nu_{U}=1}^{2} q_{U, \nu_{t} \nu_{U}}\left[B_{\nu_{U}}\left(X_{0}, c_{\nu_{U}}, \nu_{U}\right)\left(\left(1-\iota_{\nu_{U}}\right) \xi_{\nu_{0}, \nu_{U}}-\frac{c_{\nu_{0}}}{c_{\nu_{U}}}\right)+\xi_{\nu_{0}, \nu_{U}} S_{\nu_{U}}\left(X_{0}, c_{\nu_{U}}, \nu_{U}\right)\right],
\end{aligned}
$$

where $S_{\nu_{U}}\left(X_{0}, c_{\nu_{U}}, \nu_{U}\right)$ is the equity value at refinancing, given by (B18) in Appendix B.

\section{II.D Optimal Financing Decisions}

Equityholders decide on optimal refinancing boundaries as well as optimal coupons and default boundaries. The homogeneity property implies that

$$
X_{U, 2 i}\left(c_{2}\right)=X_{U, 1 i}\left(c_{1}\right) \frac{c_{2}}{c_{1}}, X_{D, 2 i}\left(c_{2}\right)=X_{D, 1 i}\left(c_{1}\right) \frac{c_{2}}{c_{1}}, i=1,2
$$


so equityholders choose effectively only six variables: $X_{D, 11}, X_{D, 12}, c_{1}, c_{2}, X_{U, 11}$, and $X_{U, 12}$.

Given the coupons and refinancing boundaries, the optimal default boundaries $X_{D, 11}, X_{D, 12}$ are determined by the following smooth pasting conditions:

$$
\left.\frac{\partial S_{1}\left(X_{t}, c_{1}, 1\right)}{\partial X_{t}}\right|_{X_{t}=X_{D, 11}}=0,\left.\quad \frac{\partial S_{2}\left(X_{t}, c_{1}, 1\right)}{\partial X_{t}}\right|_{X_{t}=X_{D, 12}}=0
$$

The conditions above guarantee that when equityholders choose the time of default their objective is to maximize the default option implicit in levered equity value.

The subsequent proposition shows how the optimal default boundary depends on current macroeconomic conditions.

Proposition 5 The optimal default boundary is state-contingent and weakly counter-cyclical, i.e. $X_{D, 1} \geq X_{D, 2}$.

Counter-cyclicality implies that the default boundary is higher in the bad state or, in other words, that starting from the same initial conditions, the distance to default is lower in a bad state and the firm is more likely to default. In their decision to default, equityholders weigh the benefits of holding on to their equity rights and all future dividends against the costs of honoring debt obligations while the firm is in financial distress. In the bad state, the present value of future earnings is lower and so the trade-off shifts, making costs more dominant, and leading to earlier exercise of the default option.

Given the coupon chosen in state $2, c_{2}$, the optimal coupon in state $1, c_{1}$, and the refinancing boundaries $X_{U, 11}$ and $X_{U, 12}$ are then chosen to maximize levered firm value at refinancing, conditional on refinancing taking place in state 1 , i.e.

$$
\left(c_{1}, X_{U, 11}, X_{U, 12}\right)=\operatorname{argmax} F_{1}\left(c_{1}, X_{U, 11}, X_{U, 12}\right),
$$

where $F_{1}=B_{1}\left(X_{0}, c_{1}, 1\right)\left(1-\iota_{1}\right)+S_{1}\left(X_{0}, c_{1}, 1\right)$. Finally, coupon $c_{2}$ is determined by maximizing levered firm value at refinancing, conditional on refinancing taking place in state 2 , i.e.

$$
c_{2}=\operatorname{argmax} F_{2}\left(c_{2}\right)
$$

where $F_{2}=B_{2}\left(X_{0}, c_{2}, 2\right)\left(1-\iota_{2}\right)+S_{2}\left(X_{0}, c_{2}, 2\right)$.

\section{Corporate Financing and Macroeconomic Fluctuations}

Sections III and IV develop the main results of this paper. By linking corporate finance decisions to asset pricing and macroeconomic fundamentals our setup allows us to address a number of important corporate finance issues relating to capital structure, default, and refinancing decisions, 
which have been at the center of recent theoretical and empirical research. In particular, we consider: (i) the impact of preferences and macroeconomic risk on financing decisions; (ii) the low-leverage puzzle, (iii) the cyclicality of firm-level and aggregate leverage, (iv) the cyclicality of the default and refinancing rates; (v) the path-dependence of corporate financing decisions; (vi) the relation between leverage and default. ${ }^{11}$ In addition, we also discuss a number of novel testable empirical implications on corporate default, refinancing, and capital structure decisions that our framework delivers. We start by studying in this section the properties of optimal decisions at a refinancing date.

\section{III.A Calibration of Parameters}

While the economic intuition of our framework is quite general, to compare it with the literature and empirical evidence it is convenient to introduce a benchmark economy. To this end, we calibrate benchmark parameter values using aggregate US data at quarterly frequency for the period from 1947Q1 to 2005Q4. Consumption is real non-durables plus service consumption expenditures from the Bureau of Economic Analysis. Earnings data are from S\&P and provided on Robert J. Shiller's website. We delete monthly interpolated values and obtain a time-series at quarterly frequency. The personal consumption expenditure chain-type price index is used to deflate the earnings time-series. Unconditional parameter estimates are summarized in Panel A of Table I. With intertemporal macroeconomic risk, we need conditional estimates, and their calibrated values are given in Panel B of Table I. We now discuss the calibration exercise, which is similar to the one in Bhamra, Kuehn, and Strebulaev (2008), in more detail.

We obtain estimates of $\lambda_{1}, \lambda_{2}, g_{1}, g_{2}, \theta_{1}, \theta_{2}, \sigma_{C, 1}, \sigma_{C, 2}, \sigma_{X, 1}^{s}, \sigma_{X, 2}^{s}$, and $\rho_{X C}$ by maximum likelihood. The approach is based on Hamilton (1989) and details specific to our implementation are summarized in Appendix A of Bhamra, Kuehn, and Strebulaev (2008). Our estimates are similar to those obtained by other authors who jointly estimate consumption and dividends with a state-dependent drift and volatility, as opposed to consumption and earnings (see Bonomo and Garcia (1996)). We calibrate idiosyncratic earnings volatility so that the total asset volatility is approximately $25 \%$, the average asset volatility of firms whose corporate debt is rated (see Schaefer and Strebulaev (2008)). ${ }^{12}$ This yields an idiosyncratic earnings volatility of $22.8 \%$. Andrade and Kaplan (1998) report default costs of about $20 \%$ of asset value. Moreover, Thorburn (2000), Altman, Brady, Resti, and Sironi (2002) and Acharya, Bharath, and Srinivasan (2007) find that

\footnotetext{
${ }^{11}$ For a discussion of these issues see, for example, Goldstein, Ju, and Leland (2001), Korajczyk and Levy (2003), Leary and Roberts (2005), Hennessy and Whited (2005), Hackbarth, Miao, and Morellec (2006), Hennessy and Whited (2007), Strebulaev (2007), and Chen, Collin-Dufresne, and Goldstein (2008).

${ }^{12}$ Alternatively, one may use a higher estimate of asset volatility to reflect higher cash flow risk of non-rated firms. This, not surprisingly, leads to lower leverage ratios at refinancing dates but does not affect any relative results.
} 
bankruptcy costs, $1-\alpha_{\nu_{t}}$, are counter-cyclical, i.e., $\alpha_{1}<\alpha_{2}$. Pulvino (1998) also provides evidence that bankruptcy costs for the airline industry are counter-cyclical. Consequently, we assume $\alpha_{1}=$ 0.7 and $\alpha_{2}=0.9$. Unconditional average debt issuance costs are in the order of $1.3 \%$ (Altinkilic and Hansen (2000)). We assume that the issuance cost, $\iota_{\nu_{t}}$, is $3 \%$ (1\%) in a contraction (expansion). An obvious explanation is that it takes more effort and time to refinance firm's debt obligations in a contraction, as anecdotal evidence strongly suggests. Another rationale is provided by the credit channel literature which finds that on average it is more difficult for firms to borrow following negative shocks to the economy (e.g. Gertler and Gilchrist (1993), Gertler and Gilchrist (1994)). The corporate tax rate, $\eta$, is set at $15 \% .{ }^{13}$ The annualized rate of time preference, $\beta$, is 0.01 . We assume that relative risk aversion, $\gamma$, is equal to ten and the EIS, $\psi$, is equal to 1.5, as in Bansal and Yaron (2004).

\section{III.B Optimal Capital Structure at Refinancing}

While the aim of this paper is to analyze corporate financing in dynamics, a natural way to start is to consider optimal financial decisions at refinancing points when firms actively change the amount of outstanding debt. Indeed, most studies (e.g. Goldstein, Ju, and Leland (2001), Hackbarth, Miao, and Morellec (2006), and Chen (2008)) consider only the implications at times of refinancing. Table II reports optimal corporate decisions for an individual firm in our economy at a typical refinancing date both for the static and dynamic capital structure cases. The definition of leverage that we use is based on the market values of debt and equity. ${ }^{14}$ Since the level of cash flows at refinancing is a numeraire, we normalize it to one and show default and refinancing boundaries relative to this level. There are several noteworthy results in this table.

\section{III.B.1 Dynamic vs Static Optimal Financing}

The first set of results concerns the comparison between decisions in the static case (when the firm is allowed to choose optimal leverage only once) and the more realistic dynamic case (when the firm optimally chooses not only the amount of debt but also the timing of refinancing). ${ }^{15}$ Table II shows that the optimal leverage ratio in the static case is substantially higher than in the dynamic one. This result is consistent with Goldstein, Ju, and Leland (2001), Hackbarth, Miao, and Morellec (2006), and others. In order to compare our optimal leverage ratio under dynamic capital structure with the one reported in the theoretical literature, we compute the 'unconditional' leverage ratio.

\footnotetext{
${ }^{13}$ In essence, this is also the tax benefit to debt, net of the marginal personal interest tax rate.

${ }^{14}$ Typically, market values of debt are not available and book values are used, leading to the so-called quasi-market leverage ratio, defined as the ratio of the par value of outstanding debt to the sum of this par value and the market value of equity. The difference between the market and quasi-market leverage ratios is, however, generally very small.

${ }^{15}$ The static case in our framework is equivalent to setting refinancing costs, $\iota_{\nu_{t}}$, to infinity in both states.
} 
This is the weighted average of state-dependent optimal leverage ratios, where the weights are equal to the actual long-run probability of the economy remaining in each macroeconomic state. In other words, it gives us the average optimal leverage ratio an observer should see at refinancing dates in our economy over a long period of time. This unconditional leverage ratio at the refinancing point is equal to 0.28. It can be compared with 0.37 in the model of Goldstein, Ju, and Leland (2001) and 0.26 in Strebulaev (2007). Importantly, we model neither partial loss offset (Goldstein, Ju, and Leland (2001) do model this) nor liquidity crisis costs (Strebulaev (2007) does include this), both of which would have increased the costs of financial distress and reduced optimal leverage even further. The unconditional leverage ratio in the static case, on the other hand, is substantially larger at 0.42 .

Two economic mechanisms drive firms to use debt more conservatively at refinancing in the dynamic case. First, in the dynamic case, equityholders hold a refinancing option which allows them to lever up in good times. This option makes it possible to reduce the expected costs of financial distress by issuing a smaller amount of debt at each refinancing. Related, the presence of the real option to refinance gives rise to yet another difference between the static and dynamic capital structure policies: for the same amount of debt, firms following a dynamic policy postpone default until much later, since the possibility to refinance in the future makes the default option equityholders possess more sensitive to good news.

The second mechanism, which leads to the conservative use of debt is the intertemporal macroeconomic risk faced by the representative agent. Since the agent dislikes bad news about consumption growth, the pricing kernel is higher in the bad state (the risk distortion factor, $\omega$, is higher) and Arrow-Debreu default claims rise in value. In other words, issuing debt in anticipation of future bad macroeconomic shocks, the timing of which is unexpected, is now substantially riskier, and so it is optimal to reduce dependence on leverage. This mechanism explains why optimal leverage at refinancing in our economy is lower than in e.g. Goldstein, Ju, and Leland (2001).

An important empirical discussion has centered on the conservative nature of corporate debt policies relative to optimal debt levels implied by trade-off considerations. For example, Graham (2000) finds that firms too often seem to "leave money on the table" by not levering up to the optimal level. This stylized fact has often been referred to as the "low-leverage puzzle" and recent theoretical literature has attempted to resolve this puzzle along a number of dimensions. ${ }^{16}$ Based on the comparison between dynamic and static corporate policies in Table II it is tempting to conclude that the low-leverage puzzle is easily explained by embedding the standard dynamic capital structure model inside a consumption-based model with intertemporal macroeconomic risk and an Epstein-Zin-Weil representative agent, especially if other imperfections such as partial tax

\footnotetext{
${ }^{16}$ See, e.g., Goldstein, Ju, and Leland (2001), Morellec (2004), and Ju, Parrino, Poteshman, and Weisbach (2005).
} 
loss offset are taken into account. ${ }^{17}$ As we argue below in Section IV, however, this conclusion is based on the premise that firms are usually at their refinancing points (which they are not) and in most cases overturned when we consider the aggregate dynamics of the model (which is closer to the empirical data).

\section{III.B.2 Optimal Financing and Business Conditions}

The second set of results that Table II shows relate to how optimal financing decisions depend on current business conditions. Importantly, here the decision to refinance is taken exogenously (so that $X_{U}$ is fixed and, in particular, independent of macroeconomic factors). In other words, the table allows us to compare the optimal financing decisions of two identical firms, conditional on these firms having decided to refinance under different macroeconomic conditions. Capital structure decisions at refinancing dates are unambiguously pro-cyclical: if a firm chooses its financing at the time of a contraction, its leverage ratio is lower by 0.10 or almost by a third compared to leverage at the times of expansion.

There are two opposing economic mechanisms which impact financial policies in bad and good states. First, since equity is a residual claim, its value is more sensitive to changes in macro factors than the value of debt. Therefore, for each level of coupon payment, relatively lower equity value in a contraction mechanically translates into higher leverage. Second, firms prefer to choose optimally lower coupons in contractions to increase financial flexibility. This optimal choice reflects the timevarying trade-off between costly default and tax benefits to debt. The first mechanism leads to counter-cyclical optimal leverage at refinancing, while the second mechanism renders leverage procyclical. As the table shows, it is the second economic effect which dominates and thus corporate financial policy is more conservative in a bad state. In particular, in a bad state the optimal coupon is 0.70 versus a coupon of 1.24 in an expansion. As Section III.B.3 shows, this result is robust to various perturbations in the benchmark economy's parameters. In Section IV, however, we reconsider these results on the cyclicality of leverage in a dynamic economy and compare them with the empirical evidence.

The table also shows that default and refinancing boundaries are counter-cyclical in earnings levels, leading to a number of empirical predictions. Default occurs at a higher earnings level in contractions since the real option of waiting is lower. In the context of structural models of credit risk, it is equivalent to saying that distance to default is lower in bad states, ceteris paribus. Conversely, in a boom the default option is larger and equityholders are ready to default only under particularly bad earnings outcomes. Similarly, the optimal earnings refinancing boundary is higher

\footnotetext{
${ }^{17}$ In fact, Chen (2008) does make exactly this claim.
} 
in bad times since the expected costs of financial distress and default are higher and the distance to default is lower and so better news is required for firms to refinance in bad times.

Taken together, this means that we should expect longer waiting times between leverageincreasing transactions in poor macroeconomic (and by extension, industry) conditions and, conversely, lower distance to defaults and more frequent distress refinancings in bad times. We also expect to observe large swings in leverage choice from recessions to booms. ${ }^{18}$

Interestingly, while the earnings default boundary is counter-cyclical, the precautionary savings motive means that the discount rate, $r_{A, i}$ (see Equation (11)) is also counter-cyclical, implying that the asset-value default boundary can in fact be pro-cyclical. ${ }^{19}$ Note that in single-state models (such as Merton (1974), Leland (1994)), earnings and asset-value default boundaries are typically proportional to each other. This implies that, when macroeconomic risk is non-trivial, empirical researchers studying default, both in corporate finance and credit risk implications, need to be particularly careful when they define empirical measures of default boundaries.

Another set of results implied by Table II concerns financial decisions at the time the economy switches from one state to another. When the economy switches into a contraction, firms can default even if their earnings do not change. Conversely, when macroeconomic conditions improve, firms can refinance even though their earnings stay constant. To see why, suppose that we are in a boom (state 2), with default boundary $X_{D, 2}$ and $X_{D, 2}<X<X_{D, 1}$, where $X$ is the current level of earnings. If the economy stays in a boom, the firm stays solvent. But as soon as the economy switches into the bad state (state 1), the firm declares bankruptcy. In addition to firms deciding to default without experiencing any noticeable changes to their earnings, defaults cluster in the presence of intertemporal macroeconomic risk. Thus, the model can explain the frequently observed clustering of defaults (see e.g. Das, Duffie, Kapadia, and Saita (2008)). The effect is similar to the one in Hackbarth, Miao, and Morellec (2006), where defaults cluster because of jumps in cash flows. There are, though, two important differences between our results and those of Hackbarth, Miao, and Morellec (2006). First, in our model, defaults cluster not only because of a cash flow effect, but also because of jumps in the state-dependent pricing kernel. This magnifies default clustering relative to Hackbarth, Miao, and Morellec (2006) and links it to preferences, expected consumption growth, and volatility. Second, the decision to default in our case is affected by the decreased present value of future cash flows, driven by changes in growth rates, in contrast

\footnotetext{
${ }^{18}$ In our model, firms respond to changing macroeconomic conditions either by adjusting their optimal capital structure or their default and refinancing thresholds. In reality, a number of other related controls are available. One example could be having substantially tighter covenants on bank lines of credit in recessions, which implicitly reduces available capital. Indeed, Zhang (2008) shows that covenants on credit lines are negatively related to business conditions at the time of contract negotiations. These alternative controls should be kept in mind in designing empirical tests.

${ }^{19}$ Chen, Collin-Dufresne, and Goldstein (2008), on the other hand, impose a counter-cyclical asset-value default boundary in their habit-formation model of credit risk in order to generate realistic credit spreads and default likelihoods.
} 
with Hackbarth, Miao, and Morellec (2006), where the earnings level switches. Modeling the effect of future growth rates on the decision to default may partly explain why defaults are sometimes observed to happen "too late" relative to a supposedly efficient timing outcome since the real option value of default evaporates very slowly. Related, the model predicts that we should observe a higher frequency of defaults when the economy is in a bad state and, conversely, a higher frequency of refinancing activities during boom times. Section IV.D derives the implications of our framework for the time-variation of financing variables such as aggregate default frequency.

\section{III.B.3 Comparative Statics of Optimal Financing Decisions}

In this section we explore the economics of the sensitivity of equilibrium financial decisions at a refinancing point with respect to preferences, macroeconomic parameters, and issuance costs.

The Impact of Preferences. Our framework allows us to study how changes in agents' preferences affect financial decisions. Figures 1 and 2 show the impact of the relative risk aversion coefficient, $\gamma$, and the elasticity of intertemporal substitution (EIS), $\psi$, respectively. There are two distinct mechanisms through which a change in risk aversion affects financial policy. First, as the representative agent becomes more risk averse (higher value of $\gamma$ ), a greater demand for precautionary savings drives the risk-free rate lower. Second, the risk-neutral earnings growth rate, $\hat{\theta}$, is reduced. Importantly, in pure structural models (e.g. that of Leland (1994)), the risk-free rate plays these two roles simultaneously, as a risk-free discount rate and as a cum-dividend risk-neutral growth rate. Our framework allows us to disentangle these two distinct economic effects. A lower risk-neutral growth rate increases the optimal default boundary. A lower risk-free rate increases the present value of both promised coupon payments and the equityholders' residual claim, so its total effect depends on the trade-off between, on the one hand, higher indebtedness, and, on the other hand, a larger dividend payoff. If the risk-neutral earnings growth rate is sufficiently low, as it is in our case, the value of the dividend payout is low and thus the optimal default boundary increases with risk-aversion. ${ }^{20}$ Similarly, higher risk aversion makes the refinancing option less valuable and increases optimal refinancing thresholds in both states.

For similar reasons, higher risk aversion leads to a lower optimal coupon, and therefore to a lower debt value. As Figure 1 shows, however, the leverage ratio is actually either increasing in risk aversion or barely affected. This is a surprising result since, considered alone, it would indicate that higher risk-aversion leads to a higher propensity to using debt. To explain this result note

\footnotetext{
${ }^{20}$ Interestingly, in a single-state model, the opposite is true implying a negative relation between risk aversion and the optimal default boundary. To see the intuition, consider a scenario where the earnings growth rate, $\theta$, in a singlestate world is chosen such that it equals the average $\theta$ in the multi-state world. However, since the risk-averse agent places more weight on bad states, average $\hat{\theta}$ in the risk-neutral multi-state world is lower than $\hat{\theta}$ in the single-state world.
} 
that while a lower optimal coupon reduces debt value, greater risk aversion reduces the value of claims which pay more in good states than in bad states such as equity. A fall in equity value offsets the decline of debt value, and so leverage does not change much or actually increases with respect to relative risk aversion. This result demonstrates that leverage, as a stand-alone measure, is not always sufficient as a descriptor of corporate financial policies.

We can understand the effect of the elasticity of intertemporal substitution (EIS), $\psi$, in a similar way. Increasing EIS makes the agent more tolerant of a consumption profile which is low today, but high tomorrow. Consequently, there is greater demand for risk-free savings, which lowers the risk-free rate. Since the state-contingent risk-neutral growth rate is not affected, however, a lower risk-free rate increases the value of a growing dividend payout by more than the value of indebtedness and, consequently, lowers the optimal default boundary. At the same time, there is a second mechanism in place. When EIS is higher, the agent has a stronger preference for the early resolution of intertemporal risk, and so, the long-run risk-neutral probability of being in the bad state is higher. This decreases the average value of the long-run risk-neutral growth rate, $\hat{\theta}$, and thus increases the optimal default boundary. Since the first effect is dominant, the optimal default boundary falls with EIS. For the same reasons, increasing EIS leads to an increase in the optimal coupon in both states. Also, leverage is affected by EIS much more than by risk aversion, since state-contingent growth rates in the risk-neutral world are independent of EIS and so there is a rapid increase in the value of equity as EIS rises.

The above results are all obtained in a representative agent setting. However, it is natural to expect that in a cross-section of firms run by managers (or owned by investors) with heterogeneous preferences, this heterogeneity drives differences in financial policies, in line with the above economic intuition. Preferences are thus a hitherto unexplored cross-sectional determinant of capital structure. Since our results suggest the effect is quantitatively non-trivial, it is worthwhile to explore the possibility of controlling for preferences in an empirical setting.

The Impact of Macroeconomic Factors. To see how variation in fundamental macroeconomic risk affects financial decisions, consider the comparative statics with respect to parameter $p$. A lower $p$ means macroeconomic news arrives more slowly leading to later resolution of uncertainty and thus greater intertemporal risk. This affects financial structure in two ways. First, the longrun probability of being in the bad state, $\hat{f}_{1}$, is higher since the agent places more weight on bad outcomes. Second, a higher demand for pre-cautionary savings leads to a smaller risk-free rate. Both of these effects make earlier default optimal and lead to a more conservative financial policy by reducing the optimal coupon value, as Figure 3 shows. A lower value of $p$ also leads to a dramatic decrease in equity value since equity's payoff is smaller in bad states, where consumption is most 
valuable. On balance, therefore, optimal leverage changes very little as intertemporal risk increases even though firms behave unambiguously more conservatively.

Our benchmark calibration of $p$ (equal to 0.7646 ) and $f_{1}$ (equal to 0.3555 ) translates into an average duration for contractions of just under two years and for expansions of just over four years, broadly consistent with the long-term NBER data on U.S. economic activity. Therefore, this benchmark calibration can be described as a Business Cycle (BC) calibration. Alternatively, this model can capture longer run changes in macroeconomic fundamentals through lower values of $p$, implying a longer time spent in each state on average, but keeping the long-run probability of being in each state unchanged. If we set $p$ equal to 0.2547 , the rate at which the economy converges to its steady-state distribution coincides with the one implied by the Long Run Risk (LRR) calibration of Bansal and Yaron (2004). One benefit of a LRR calibration is that it better explains high credit spreads and the levered equity premium (see Bhamra, Kuehn, and Strebulaev (2008)). As Figure 3 shows, however, at the same time it has only a small effect on leverage and thus has little or no impact on the low-leverage puzzle. Moreover, since equity value is more sensitive to intertemporal risk in the bad state, when $p$ is low, equity value in the bad state shrinks which increases leverage. Conversely, in the good state, equity value is less sensitive to intertemporal risk, and so leverage in the good state actually falls for low values of $p$.

The response of financial policy to changes in other macroeconomic factors is straightforward. Firms become more conservative as earnings and consumption growth rates become lower, the correlation between earnings and consumption increases, and the long-term probability of spending time in the bad state increases. Higher volatility of earnings growth in the bad state increases the option value of waiting and therefore decreases the default boundary in that state. At the same time, it makes the default option relatively less valuable in the good state and thus increases the good state's default boundary.

Constrained vs Unconstrained Firms. Empirical studies in corporate finance often classify firms into financially constrained and unconstrained firms based on the cost of accessing external financial markets. Size, access to public bond markets, the level of dividend distributions, the degree of bank dependance, profitability, and the market-to-book ratio have been used as proxies for financial constraints. ${ }^{21}$ Hennessy and Whited (2007) investigate the nature of financial constraints by applying the simulated method of moments to a dynamic model of financing and find, in particular, that small firms face larger financial constraints. Motivated by this evidence, in our framework, a natural reduced-form proxy for financial constraints are state-dependent debt issuance

\footnotetext{
${ }^{21}$ See, for example, Fazzari, Hubbard, and Petersen (1988), Korajczyk and Levy (2003), Almeida, Campello, and Weisbach (2005), and Almeida and Campello (2007).
} 
$\operatorname{costs}, \iota_{\nu_{t}}$. The evidence from the credit channel literature suggests that firms which face greater financial constraints find it more difficult to tap external financial markets in bad times (Gertler and Gilchrist (1993), Gertler and Gilchrist (1994), Bernanke and Gertler (1995)). Figure 4 shows how financing decisions change as the cost of financing during a negative shock, $\iota_{1}$, changes, while the cost during a positive shock, $\iota_{2}$, remains constant. The underlying idea is that during booms, both the supply of loans from depository institutions (the bank lending channel) and the collateral value (the balance sheet channel) are higher, making it relatively cheap to raise financing for all firms. Constrained firms are likely to be the first to suffer from a decrease in the supply of banking loans and are more likely to have pro-cyclical collateral values, so the differential in access to debt markets is more visible in bad times.

As Figure 4 demonstrates, unconstrained firms (for which debt issuance cost is independent of the macroeconomic regime) exhibit substantially less pro-cyclical behavior in coupon levels and almost no cyclical pattern in leverage at refinancing points, since a low coupon in the bad state implies a higher leverage ratio. Constrained firms, on the other hand, exhibit very strong pro-cyclical behavior, consistent with both empirical evidence (Korajczyk and Levy (2003)) and theoretical predictions (e.g. Kiyotaki and Moore (1997)). For example, if $\iota_{1}=0.08$, optimal leverage is 0.11 in a contraction and 0.34 in a boom, a $23 \%$ difference compared to a $10 \%$ differential for the benchmark case. As the figure shows, a higher degree of pro-cyclicality exhibited by financially constrained firms is driven by decisions taken in both states. Not only do constrained firms substantially decrease their reliance on debt in bad times, but they also increase optimal debt issuance in good times in order to finance themselves while credit is relatively cheap. Finally, higher pro-cyclicality in the leverage of constrained firms leads to higher expected returns on their equity and a higher degree of co-movement in their returns, consistent with the findings of Whited and Wu (2006).

\section{Aggregate Dynamics of Optimal Capital Structure}

In this section we explore the empirical properties of our framework in aggregate dynamics. All the results in Section III are obtained under the assumption that the firm is at a refinancing point. As has been shown by Strebulaev (2007) in the context of a single-state dynamic capital structure model, using any implications of comparative statics at the point of refinancing can result in substantially misleading empirical implications. This is because firms in the real world frequently optimally deviate from refinancing point equilibria and their deviations are not symmetric and do

not cancel each other in the cross-section. Empirically, it is difficult to identify clearly refinancing points where "target leverage" can be estimated. Therefore, it is crucial to control for the time 
evolution of the cross-sectional distribution of firms in the economy. ${ }^{22}$ In this section, we study the aggregate dynamics of firms by investigating the cross-sectional properties of corporate financial policies in a way that makes our results comparable with empirical evidence. For this reason, an alternative way to think about aggregate dynamics is that it represents the "true" dynamic implications of any framework in which firms may optimally delay financial or investment decisions.

To give one example of how infrequent refinancing may affect the economic implications of the model, consider the comparative statics exercise with respect to risk aversion. The previous section argues that as risk aversion increases, firms pursue more conservative financial policy and at the same time the equityholders' residual value is lower, and since these two effects work in opposing directions, the optimal leverage ratio at refinancing remains almost the same. However, these two effects have very different temporal properties. If risk aversion suddenly increases, the pricing kernel and thus the pricing of equity and debt claims is affected immediately, but book values of debt are unlikely to change (unless the firm defaults). So the leverage ratio jumps upwards at that very moment. As time passes, firms start refinancing to new more conservative debt levels, and leverage reduces over time to its previous value. It is clear from this example that a simple comparative statics exercise misses this temporal dimension and thus tells us nothing about aggregate effects.

To study the aggregate dynamic implications of our model, we generate artificial data, taking as the starting point the dynamic financing results reported in Table II. There are two interrelated sources of systematic shocks that our firms experience, a systematic component in the earnings level of firms and changes in macroeconomic fundamentals. To model such dependencies, shocks to firms' earnings are drawn from a distribution that has a common systematic component. In each period the state of the economy may also randomly switch. Crucially for our investigation, since all firms are identical at the refinancing point, the cross-sectional differences in leverage are attributable only to different evolutions in their asset values and path dependency in macroeconomic fundamentals. Importantly, while macroeconomic factors are obviously common across all firms, sensitivity of firms' realized financial policies to these factors can be profoundly different. For example, firms which are already in financial distress may respond to the economy switching into a recession by immediately defaulting because of tightened credit conditions and reduced growth prospects while a macroeconomic shock of the same magnitude may barely affect financially healthy firms.

\section{IV.A Simulating a Dynamic Economy}

To analyze model-implied aggregate dynamics, the benchmark simulation is run as follows. In any economy, at date zero, the initial macroeconomic state is chosen, and all firms are 'born' and

\footnotetext{
${ }^{22}$ Berk, Green, and Naik (1999) and Bertola and Caballero (1994) use a similar idea to study stock returns and aggregate investment dynamics, respectively.
} 
choose their optimal capital structure. The comparative statics of the system at date zero (where all firms are at their refinancing points) is thus analogous to that described in Table II. To minimize the impact of the initial conditions, we first simulate 400 quarters of data for 3,000 firms and use the cross-section at the last quarter as the starting date for the dynamic analysis. To control for the presence of systematic shocks and study sensitivity to macroeconomic history, we repeat the simulation a large number $(1,000)$ of times. This allows us to study the sampling distribution for statistics of interest produced by the model in a dynamic economy.

At the start of every period the state of the economy over the past quarter is determined. Then each firm observes its state-dependent asset value dynamics over the last quarter. If the value does not cross any boundary, the firm takes no action. It is important to stress that it is optimal, under these conditions, for the firm to remain passive. If its value crosses a state-dependent upper refinancing boundary, it refinances, re-setting the leverage ratio to the optimal level at the refinancing point for this state, and so starting a new refinancing cycle. Similarly, if its value crosses a state-dependent default boundary, the firm defaults. For simplicity, we assume that the number of firms in the economy remains constant by allowing bondholders to take over defaulted firms so that they emerge in the same period as new firms at their refinancing points.

\section{IV.B Aggregate Dynamics vs Refinancing Dates}

Table III reports the cross-sectional averages of financial variables in a dynamic economy's steady state. The first insight is obtained by comparing average leverage ratios in a dynamic economy and at a refinancing date reported in Table II. In particular, the first two columns of III report averages across all economies conditional on the current state. The comparison with similar columns in Table II shows that leverage is substantially higher under aggregate dynamics in both bad and good times, rising from $22 \%$ to $44 \%$ in contractions and from $32 \%$ to $38 \%$ in booms. Unreported in the table, unconditional leverage in aggregate dynamics (which reflects the long-run actual probabilities of the economy remaining in each state) is $40 \%$ as opposed to unconditional leverage of $28 \%$ at a refinancing point. This result demonstrates that the findings of Strebulaev (2007) are not confined solely to a pure structural model, but hold more generally in a structural-equilibrium framework where macroeconomic conditions vary. Crucially, it shows that it is misleading to make any quantitative statements based on refinancing point values. In particular, incorporating switching in macroeconomic regimes is unlikely on its own to account better for the low-leverage puzzle than the state-independent model. ${ }^{23}$ There are several reasons behind the difference. Leverage

\footnotetext{
${ }^{23}$ One example is a contemporaneous paper by Chen (2008) who attempts to resolve the low-leverage puzzle by considering macroeconomic factors similar to the ones we model here and comparing refinancing point leverage with empirical data. As our results clearly show, the correct exercise is to compare model-implied leverage in aggregate dynamics to the empirical data. Under aggregate dynamics, Chen's model should also deliver substantially higher leverage ratios.
} 
dynamics are inherently asymmetric, since it is more difficult to restructure upwards than downwards and optimal leverage at refinancing points is relatively low. Unsuccessful firms tend to delay restructuring while successful firms restructure fairly soon. Moreover, firms at different stages in their refinancing cycle react differently to economic shocks of the same magnitude, and, in particular, since the equity value of financially distressed firms is sensitive to shocks, their leverage ratios are more affected by negative news. In addition, these effects are exacerbated here since firms that restructure in booms also choose a relatively lower refinancing boundary. Finally, firms that restructure in booms are more sensitive to changes in macroeconomic conditions since their financial policy is riskier.

The second set of results emerges when we compare leverage ratios in different states. While optimal leverage is pro-cyclical at the refinancing point, it is actually counter-cyclical in dynamics for the whole cross-section. The average leverage ratio is 0.44 in a bad state, while the average leverage ratio in a good state is 0.38 . The direction of cyclicality differs between aggregate dynamics and refinancing points, since when the economy switches from good to bad states, the market value of equity drops more than the market value of debt, thus making leverage more counter-cyclical. This mechanical effect dominates the optimal choice of debt for a cross-section of firms. Note that if we consider the subsample of financially constrained firms then, as we show in Section III.B.3, they follow much more pro-cyclical leverage at a refinancing point. Therefore, we would expect such firms to exhibit less strongly counter-cyclical behavior in aggregate dynamics consistent with empirical evidence. The difference between aggregate dynamics and refinancing points explains why it is not an easy task to study the relation between macroeconomic conditions and leverage in the empirical data and why various studies get seemingly inconsistent results. Our result on the counter-cyclicality of the whole cross-section is consistent, for example, with Korajczyk and Levy (2003) who find leverage to be counter-cyclical for relatively unconstrained firms. On the other hand, Covas and Den Haan (2007) and Korteweg (2008) find empirically that when firms choose optimal leverage, then leverage decisions are pro-cyclical, consistent with our refinancing date equilibrium result. Moreover, Korajczyk and Levy (2003) also find that financially constrained firms follow pro-cyclical financial policies. Our results identify the nature of the tension which makes it hard to provide clear-cut empirical evidence and suggests that it would be interesting to study the relation between these two effects by considering historical evidence on financial decisions over the business cycle.

The first two columns of Table III also show the relative frequency of financing events conditional on the state of the economy. The variable Economy state reports the average fraction of time an average economy spends in each state. As we would expect, it is equal to 0.36 for state 1 since it is driven by the long-run probability of remaining in state $1, f_{1}$, which is equal to 0.355 in our 
benchmark calibration. Similar statistics on default and refinancing frequencies tell us, however, a very different story. While bad states occur less frequently than good states, defaults are more likely to happen in bad states. Of all defaults, 56\% happen in bad times or, in other words, default in bad times happen more than $50 \%$ more frequently than we would expect had defaults been independent of macroeconomic conditions. This strongly implies that default decisions are counter-cyclical. Conversely, firms are much more likely to refinance in good times, with $84 \%$ of all refinancings occurring in state 2 , demonstrating the pro-cyclical nature of refinancing decisions.

The values of financing variables depend on a particular realization of systematic shocks in each economy. Existing empirical evidence is based obviously only on one economy. Therefore Table III also reports 25th and 75th percentiles for all variables to enable us to study to what extent our results are robust with respect to realizations of macroeconomic shocks. For example, to get the 25 th percentile of average leverage in any state, we first estimate average leverage in this state for all 1,000 simulated economies and report the 25th percentile of this sampling distribution. There are two noteworthy results. First, there is a wide distribution of all variables of interest. For example, the fraction of defaults that occurs in state 1 varies between $45 \%$ and $70 \%$. Such a variation tends to reduce the statistical power of empirical tests. Second, the cyclicality implications are not affected. For example, defaults are still more likely to occur in bad states relative to the frequency expected under the uniform distribution.

\section{IV.C Path-Dependency in Financing Decisions}

The last four columns in Table III report average leverage as well as the frequency of corporate events conditional on both the current state of the economy and the state at previous refinancing. Note that while the current state of the economy is common across all firms, the state at previous refinancing is specific to each firm, since firms refinance at different times. For example, the fourth column (denoted by $2 \rightarrow 1$ ) takes the subsample of all economy-years for which the current state is 1 (contraction) and, for each such economy, takes a subsample of firms which last refinanced when the economy was in state 2 (expansion). These results bear evidence on two issues: path dependence of financial structure and the relation between financing and macroeconomic conditions.

There is substantial hysteresis in the model-implied leverage ratios. ${ }^{24} \mathrm{In}$ particular, firms which choose leverage in a contraction are more likely to have lower debt capacity (for example, because they have higher volatility) and thus by choosing lower leverage they protect themselves against adverse changes in macroeconomic conditions. Conversely, firms which refinance in a boom are more likely to expose themselves to a higher likelihood of financial distress in a subsequent bad

\footnotetext{
${ }^{24}$ Recent empirical evidence (e.g. Welch (2004), Lemmon, Roberts, and Zender (2008)) points to the existence of hysteresis consistent with dynamic capital structure models of infrequent refinancing (see Strebulaev (2007)).
} 
state. For example, conditional on the current state being a contraction, firms that refinanced in a bad state in the past have substantially lower leverage than firms that refinanced in a boom $(0.41$ vs 0.46$)$. The table also shows that the difference is smaller in booms (0.36 vs 0.39$)$ since the effect of choosing higher leverage in a boom is mitigated by higher equity value.

These results also provide two further empirical implications which are yet to be tested. First, the cross-sectional variation of capital structure is larger in bad times. Second, our results also point to the co-movement of capital structure across firms over the business cycle. Moreover, this co-movement is expected to be higher in bad times when equity values are affected by higher systematic volatility. To sum up, we hypothesize that empirically one would find that macroeconomic conditions during past financing events are an important determinant of current capital structure.

Table III also clearly shows that default and refinancing decisions are also subject to a hysteresis effect and exhibit substantial time-variation in response to macroeconomic factors. Defaults occur substantially more frequently in bad times, and in particular, if firms previously refinanced in good times. On the other hand, firms are less likely to default in good times if they refinanced in good times. In the case of refinancings (unrelated to financial distress), firms are more likely to increase leverage in an expansion if they previously refinanced in the bad state. Taken together, all these results clearly indicate that the cyclicality of financing variables is path-dependent.

\section{IV.D Time-Variation of Financial Structure}

In this section we explore the time-variation of dynamic financial structure for the aggregate economy. Figure 5 shows how economy-wide leverage varies over time for a typical realization of macroeconomic shocks. Grey areas in the figure correspond to times when the economy is in a contraction (state 1). For the purpose of this analysis, we estimate aggregate leverage as the sum of all debt outstanding in this economy divided by the market value of firms' assets. ${ }^{25}$ Aggregate leverage is strongly counter-cyclical and usually jumps at the beginning of a contraction phase. This corresponds very closely with time-variation of aggregate leverage observed in the U.S. and other countries (see, for example, Korajczyk and Levy (2003), their Figure 1 on p. 77). Countercyclicality of aggregate leverage is driven by the same economic forces which make cross-sectional leverage higher in dynamics and counter-cyclical as opposed to its properties at refinancing dates. To explore the sensitivity of counter-cyclicality to the nature and magnitude of macroeconomic shocks, we generate 3,000 economies over 100 years and study the correlation between aggregate leverage and the state of the economy over the second half of each data set. The average correlation is -0.51 with a standard deviation of 0.14 and 5 th and $95 t h$ percentile values of -0.72 and

\footnotetext{
${ }^{25}$ Other measures, such as average of firms' individual leverage ratios, the weighted average of the market leverage ratio, where the weights are the market value of firms' assets, or using refinancing-date book debt values give very similar results.
} 
-0.26, respectively, confirming the conjecture that we should expect counter-cyclical behavior for any combination of macroeconomic shocks.

We also find that the aggregate default frequency is, not surprisingly, counter-cyclical, since equityholders' residual claim is of lower value in contractions. The average correlation between the default rate and the state of the economy across all generated economies is -0.65. There are two 'recession-type' effects on default rates. First, upon the economy shifting from the good to the bad state, the default boundary increases for all firms forcing a number of firms immediately into default even though their earnings have not changed. This effect causes default clustering and explains spikes of default rates at the start of bad times (see e.g. Duffie, Saita, and Wang (2007) and Das, Duffie, Kapadia, and Saita (2008)). Second, as the time spent in the bad state increases, earnings deteriorate and firms are pushed into default once again.

We also explore the conditional volatility of financial variables, which has not yet received much attention in the corporate literature. For each economy, we estimate the volatility of crosssectional leverage as well as the time-series volatility of individual firms conditional on the state of the economy. We find a non-trivial difference between state-contingent conditional volatilities. For example, the conditional volatility of cross-sectional leverage is on average 0.15 in state 2 and 0.23 in state 1 , indicating that there is also counter-cyclicality in volatilities. Similar behavior is observed for the time-series volatility of leverage as well as for the volatility of default and refinancing rates.

\section{IV.E Leverage and Default Probability}

Given the path-dependence of financing decisions and time-variation in macroeconomic factors, we would expect the probability of default (as well as refinancing) to depend both on initial and current conditions. For example, for a firm with a given level of outstanding debt, when the economy jumps into the bad state, the default probability must be higher for two reasons: the growth rate of earnings is lower and the optimal default boundary is higher due to a reduction in the default option's value. Thus, it seems reasonable to conjecture that in default-predicting regressions, actively used in empirical bankruptcy studies, there is a need to control for macroeconomic conditions.

To investigate this conjecture, we explore the relation between leverage and default conditional on both past and current macroeconomic regimes. Table IV reports the results of this exercise. For each level of leverage and each set of macroeconomic conditions, we find the level of firm's earnings that, together with state-dependent optimal financing decisions, yields a particular leverage level. An important consequence is that all results are for firms that follow optimal financial policy as implied by our model, but which are not at the refinancing point. For each observation, the table 
reports the expected cumulative default probability over five and ten years. ${ }^{26}$ Default probabilities are obtained by simulating 10,000 economies each containing 5,000 firms over 10 years for each observation. Therefore, the table reports average default probabilities and their standard deviations across all economies. For example, there is a 9.6-9.9\% chance that a firm with leverage of $50 \%$ defaults over the next ten years starting from the bad state, and a 9.3-9.4\% chance when starting from the good state.

A surprising result emerging from Table IV is that, while macroeconomic conditions obviously do matter for default likelihood, there is little additional power gained by conditioning on past and present macroeconomic conditions once leverage is accounted for. Differences between statedependent default probabilities are much smaller than would be expected from, say, the difference between optimal financing decisions in both states. The firm's leverage ratio, as long as it is based on the market value of firm's equity, is close to being a sufficient statistic for predicting future default over the entire term structure.

The economic explanation behind this result lies in how financial decisions and macroeconomic conditions influence leverage ratios. Consider again the case of the leverage ratio of $50 \%$. While the optimal leverage ratio in the bad state is lower (22\% vs $32 \%$ ), and therefore the expected default probability at the refinancing point is actually lower, a more adverse idiosyncratic shock is needed for the leverage ratio to increase to $50 \%$ compared to the firm which refinances in the good state and has initially higher leverage. These two opposing effects almost cancel each other. More generally, this intuition implies that the leverage ratio already incorporates time-variation in firm's fortunes including most information about macroeconomic shocks. It also implies that results in Table IV are consistent with those in Table III which show, that unconditional on leverage, defaults are most likely to happen in a contraction for firms which refinanced in the good state. An important caveat is that our firms differ only due to the effect of time-varying shocks. If firms differ in firm-specific parameters, such as asset volatility, then these parameters may, in addition to leverage, become significant in predicting default.

Studying default probabilities is an all-important task in credit risk applications. Empirically, the only reliable classification used to predict ratings has been the one based on credit ratings provided by S\&P and Moody's. Theoretically, a number of studies try to proxy ratings in their otherwise rating-free credit risk models to match theory and data on default rates. A potentially better approach, suggested by the results above, is likely to be side-stepping ratings (which are ambiguously defined with their meaning generally agreed to be time-varying, especially over the

\footnotetext{
${ }^{26}$ Note that we report firm-specific default probabilities which are unconditional on refinancing as opposed to bondspecific default probabilities. Empirical studies concentrate mostly on firm-specific default. In the context of credit risk, firm-specific default can be interpreted as the one relevant for pricing credit default swaps. Unreported, we also replicate the results of this exercise using the bond-specific default definition.
} 
business cycle) and tabulating the term structure of cumulative default rates based on leverage and potentially other firm-specific characteristics such as asset volatility. This empirical exercise is to some extent akin to studying empirical distance to default but in a model-free empirical framework.

Figure 6 shows the quantitative relationship between leverage and the term structure of default probabilities predicted by our model, which is yet to be tested empirically. An important consideration is that there is a large variation in aggregate defaults from one economy realization to another. There is, of course, no reason why the actual economy should be the average one. For this reason, the figure also shows the $25 t h$ and $75 t h$ percentiles for each default probability observation. The model predicts that default is a convex function of leverage, with default over the next 10 years highly unlikely for leverage lower than $30 \%$. When leverage is very low, the default probability can actually increase as leverage declines, since firms are close to their refinancing threshold.

\section{Conclusion}

In this paper we study the impact of intertemporal macroeconomic risk on the aggregate dynamics of cross-sectional capital structure. For this purpose, we build a structural-equilibrium framework, by embedding a pure contingent-claims model of dynamic capital structure in a consumption-based asset-pricing model with a representative agent. This allows us to endogenize the link between actual and risk-neutral default probabilities and study the impact of preferences and macroeconomic risk on asset valuation and consequently on optimal financing decisions.

We find that optimal financing decisions are more conservative in bad times when firms refinance their obligations. The earnings default boundary is counter-cyclical and capital structure is procyclical. However, capital structure turns counter-cyclical in aggregate dynamics, consistent with empirical evidence. We also find that financially constrained firms follow a much more pro-cyclical financial policy. The agent's preferences have a profound impact on optimal financing policies and may generate substantial cross-sectional variation in observed leverage structures. Leverage is found to incorporate most of the information on time-variation in macroeconomic conditions necessary to predict default rates. We show this by demonstrating that once leverage is controlled for, default probabilities are mostly independent of both current and past macroeconomic conditions.

Taken together, our results indicate the importance of macroeconomic conditions for optimal financial decisions, as well as a necessity to consider capital structure in aggregate dynamics. An open question for future research is to what extent these results hold when an economy is populated by heterogenous agents who endogenously decide whether they want to become equityholders or debtholders. 


\section{A Changes in the state of the economy and jumps}

Suppose that during the small time-interval $[t-\Delta t, t)$, the economy is in state $i$ and that at time $t$, the state changes, so that during the next small time interval $[t, t+\Delta t)$, the economy is in state $j$. To distinguish between the state of the economy before and after the jump, we define the left-limit of $\nu$, the state of the economy, at time $t$ as

$$
\nu_{t-}=\lim _{\Delta t \rightarrow 0} \nu_{t-\Delta t}
$$

and the right-limit as

$$
\nu_{t}=\lim _{\Delta t \rightarrow 0} \nu_{t+\Delta t}
$$

Therefore $\nu_{t-}=i$, whereas $\nu_{t}=j$, so the left- and right-limits are not equal.

If some function $E$ depends on the current state of the economy i.e. $E_{t}=E\left(\nu_{t}\right)$, then $E$ is a jump process which is right continuous with left limits. If a jump from state $i$ to $j \neq i$ occurs at date $t$, then we abuse notation slightly and denote the left limit of $E$ at time $t$ by $E_{i}$, where $i$ is the index for the state. i.e. $E_{t-}=\lim _{s \uparrow t} E_{s}=E_{i}$. Similarly $E_{t}=\lim _{s \downarrow t} E_{s}=E_{j}$. We shall use the same notation for all processes that jump, because of their dependence on the state of the economy.

\section{B Proofs}

Proofs of Propositions 1 and 2 are contained in Bhamra, Kuehn, and Strebulaev (2008).

The following proposition gives closed-form expressions for Arrow-Debreu refinancing and default claims.

Proposition B1 If $X_{U, 2}<X_{U, 1}$, then the Arrow-Debreu refinancing claims are given by

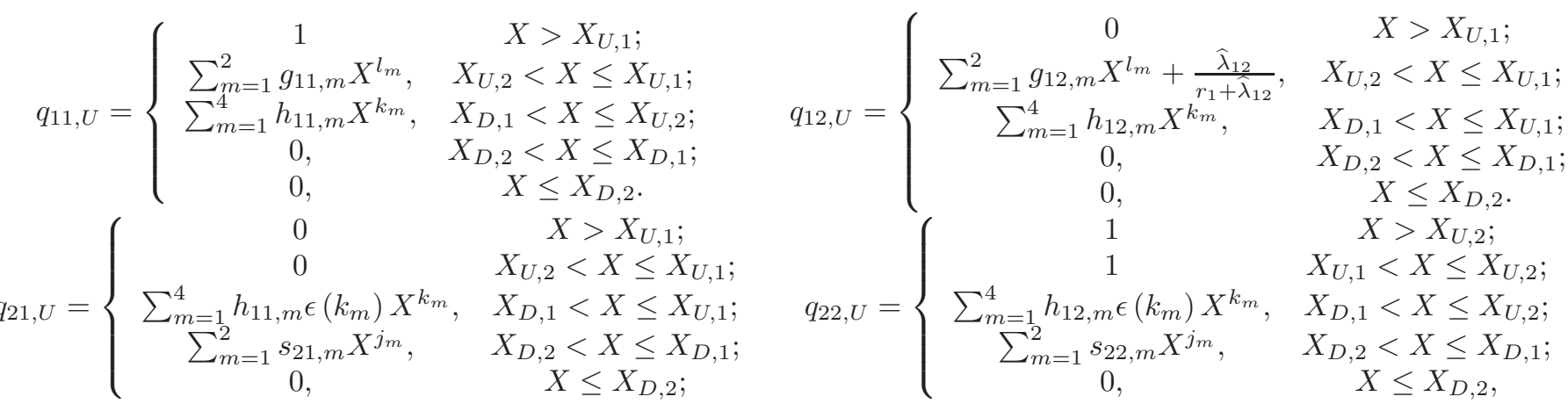

where $g_{11,1}, g_{11,2}, h_{11,1}, h_{11,2}, h_{11,3}, h_{11,4}, g_{12,1}, g_{12,2}, h_{12,1}, h_{12,2}, h_{12,3}, h_{12,4}, s_{11,1}, s_{11,2}, s_{12,1}, s_{12,2}$ are determined by (B7), and the Arrow-Debreu default claims are given by

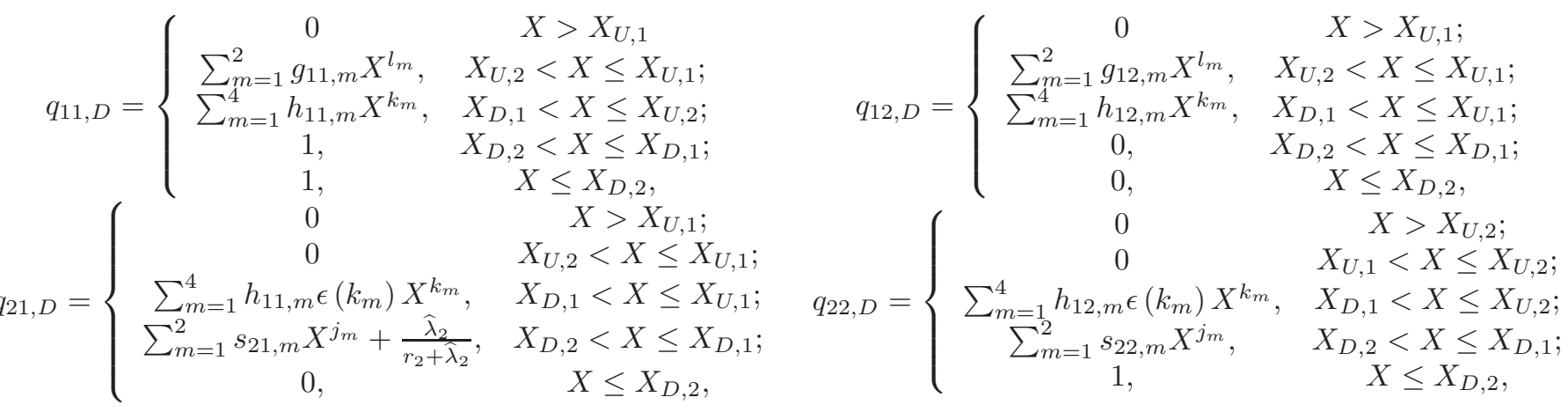


where $g_{11,1}, g_{11,2}, h_{11,1}, h_{11,2}, h_{11,3}, h_{11,4}, g_{12,1}, g_{12,2}, h_{12,1}, h_{12,2}, h_{12,3}, h_{12,4}, s_{11,1}, s_{11,2}, s_{12,1}, s_{12,2}$ are determined by (B8). If $X_{U, 1}<X_{U, 2}$, then the Arrow-Debreu refinancing claims are given by

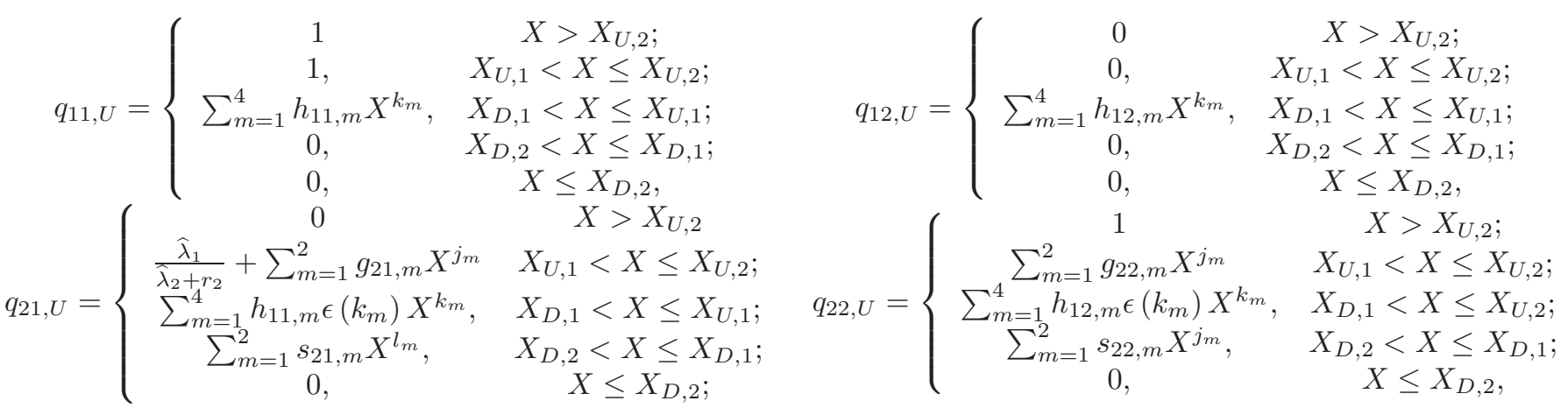

where $g_{11,1}, g_{11,2}, h_{11,1}, h_{11,2}, h_{11,3}, h_{11,4}, g_{12,1}, g_{12,2}, h_{12,1}, h_{12,2}, h_{12,3}, h_{12,4}, s_{11,1}, s_{11,2}, s_{12,1}, s_{12,2}$ are determined by (B9), and the Arrow-Debreu default claims are given by

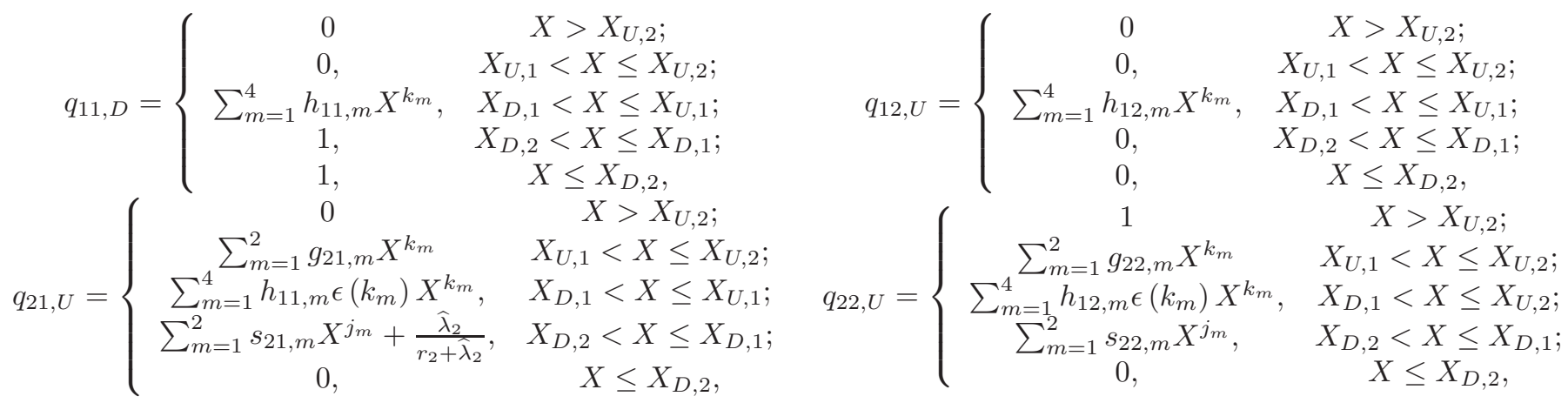

where $g_{11,1}, g_{11,2}, h_{11,1}, h_{11,2}, h_{11,3}, h_{11,4}, g_{12,1}, g_{12,2}, h_{12,1}, h_{12,2}, h_{12,3}, h_{12,4}, s_{11,1}, s_{11,2}, s_{12,1}, s_{12,2}$ are determined by (B10).

Proof of Proposition B1. We consider the cases $X_{U, 2}<X_{U, 1}$ and $X_{U, 1}<X_{U, 2}$ separately. When $X_{U, 2}<X_{U, 1}$, we must solve for Arrow-Debreu default and refinancing claims in the following 5 regions: $1 . X>X_{U, 1} ; 2 . X_{U, 2} \leq X \leq X_{U, 1} ; 3$. $X_{D, 1} \leq X \leq X_{U, 2} ; 4 . X_{D, 2} \leq X \leq X_{D, 1} ; 5 . X \leq X_{D, 2}$.

The time- $t$ price of the Arrow-Debreu refinancing claim which pays out a unit of consumption at refinancing if refinancing occurs in state $j$, conditional on the current state being $i$ satisfies the basic asset pricing equation

$$
E_{t}^{\mathbb{Q}}\left[d q_{U, i j}-r_{i} q_{U, i j} d t=0 \mid \nu_{t}=i\right] .
$$

Therefore,

$$
\frac{1}{2} X^{2} \sigma_{X, i}^{2} \frac{d^{2} q_{U, i j}}{d X^{2}}+X \hat{\theta}_{i} \frac{d q_{U, i j}}{d X}+\widehat{\lambda}_{i}\left(q_{U, k j}-q_{U, i j}\right)-r_{i} q_{U, i j}=0
$$

subject to relevant boundary conditions. In the first of the above regions, refinancing is immediate whatever the current state is. Therefore $q_{U, 11}=q_{U, 22}=1$ and $q_{U, 12}=q_{U, 21}=0$. In the second region, refinancing is immediate if the current state is 2 . Therefore, $q_{U, 22}=1$ and $q_{U, 21}=0$. To find $q_{U, 11}$ and $q_{U, 12}$, we must solve the ordinary differential equations:

$$
\frac{1}{2} X^{2} \sigma_{X, 1}^{2} \frac{d^{2} q_{U, 11}}{d X^{2}}+X \hat{\theta}_{1} \frac{d q_{U, 11}}{d X}-\left(r_{1}+\widehat{\lambda}_{1}\right) q_{U, 11}=0
$$


and

$$
\frac{1}{2} X^{2} \sigma_{X, 1}^{2} \frac{d^{2} q_{U, 12}}{d X^{2}}+X \hat{\theta}_{1} \frac{d q_{U, 12}}{d X}+\widehat{\lambda}_{1}\left(1-q_{U, 12}\right)-r_{1} q_{U, 12}=0
$$

Therefore,

$$
\left(\frac{1}{2} \sigma_{X, 1}^{2}\left[\begin{array}{ll}
1 & 0 \\
0 & 1
\end{array}\right] \frac{d^{2}}{d X^{2}}+\widehat{\theta}_{1}\left[\begin{array}{ll}
1 & 0 \\
0 & 1
\end{array}\right] \frac{d}{d X}-\left(\widehat{\lambda}_{1}+r_{1}\right)\left[\begin{array}{ll}
1 & 0 \\
0 & 1
\end{array}\right]\right)\left[\begin{array}{l}
q_{U, 11} \\
q_{U, 12}
\end{array}\right]+\left[\begin{array}{c}
0 \\
\hat{\lambda}_{1}
\end{array}\right]=\left[\begin{array}{l}
0 \\
0
\end{array}\right]
$$

The general solutions of the above equations are

$$
\begin{aligned}
& q_{U, 11}=g_{11} X^{l_{1}}+g_{12} X^{l_{2}} \\
& q_{U, 12}=g_{21} X^{l_{1}}+g_{22} X^{l_{2}}+\frac{\widehat{\lambda}_{1}}{r_{1}+\widehat{\lambda}_{1}}
\end{aligned}
$$

where $l_{1}<l_{2}$ are the roots of the quadratic

$$
\frac{1}{2} \sigma_{X, 1}^{2} l(l-1)+\widehat{\theta}_{1} l-\left(\widehat{\lambda}_{1}+r_{1}\right)=0
$$

In the third region

$$
\left(\frac{1}{2}\left[\begin{array}{cc}
\sigma_{X, 1}^{2} & 0 \\
0 & \sigma_{X, 2}^{2}
\end{array}\right] X^{2} \frac{d^{2}}{d X^{2}}+\left[\begin{array}{cc}
\widehat{\theta}_{1} & 0 \\
0 & \widehat{\theta}_{2}
\end{array}\right] X \frac{d}{d X}-\left[\begin{array}{cc}
r_{1} & 0 \\
0 & r_{2}
\end{array}\right]+\left[\begin{array}{cc}
-\widehat{\lambda}_{1} & \widehat{\lambda}_{1} \\
\widehat{\lambda}_{2} & -\widehat{\lambda}_{2}
\end{array}\right]\right)\left[\begin{array}{ccc}
q_{U, 11} & q_{U, 12} \\
q_{U, 21} & q_{U, 22}
\end{array}\right]=\left[\begin{array}{cc}
0 & 0 \\
0 & 0
\end{array}\right]
$$

The above ordinary differential equation system has the following general solution

$$
\begin{aligned}
q_{U, 1 j} & =\sum_{m=1}^{4} h_{1 j, m} X^{k_{m}}, \\
q_{U, 2 j} & =\sum_{m=1}^{4} \epsilon\left(k_{m}\right) h_{1 j, m} X^{k_{m}},
\end{aligned}
$$

where $k_{1}<k_{2}<0<k_{3}<k_{4}$ are the roots of the quartic

$$
\left[\frac{1}{2} \sigma_{X, 1}^{2} k(k-1)+\widehat{\theta}_{1} k-\left(\widehat{\lambda}_{1}+r_{1}\right)\right]\left[\frac{1}{2} \sigma_{X, 2}^{2} k(k-1)+\widehat{\theta}_{2} k-\left(\widehat{\lambda}_{2}+r_{2}\right)\right]-\widehat{\lambda}_{2} \widehat{\lambda}_{1}=0 .
$$

and $\epsilon(k)$ is defined

$$
\epsilon(k)=-\frac{\widehat{\lambda}_{2}}{\frac{1}{2} \sigma_{X, 2}^{2} k(k-1)+\widehat{\theta}_{2} k-\left(\widehat{\lambda}_{2}+r_{2}\right)}=-\frac{\frac{1}{2} \sigma_{X, 1}^{2} k(k-1)+\widehat{\theta}_{1} k-\left(\widehat{\lambda}_{1}+r_{1}\right)}{\widehat{\lambda}_{1}} .
$$

See Guo (2001) for a proof that the above quartic has 4 distinct real roots, two of which are positive, provided that $\sigma_{X, i}, r_{i}$, $\widehat{\lambda}_{i}>0$ for $i \in\{1,2\}$.

In the fourth region default is immediate if the state is 1 , but not if the state is 2 . Therefore, $q_{U, 11}=q_{U, 12}=0$ and

$$
\frac{1}{2} X^{2} \sigma_{X, 2}^{2} \frac{d^{2} q_{U, 2 j}}{d X^{2}}+X \hat{\theta}_{2} \frac{d q_{U, 2 j}}{d X}-\left(r_{2}+\widehat{\lambda}_{2}\right) q_{U, 2 j}=0
$$

The general solution of the above ordinary differential equation is

$$
q_{U, 2 j}=\sum_{m=1}^{2} s_{2 j, m} X^{j_{m}}
$$


where $j_{1}<j_{2}$ are roots of the quadratic

$$
\frac{1}{2} \sigma_{X, 2}^{2} j(j-1)+\widehat{\theta}_{2} j-\left(\widehat{\lambda}_{2}+r_{2}\right)=0
$$

In the fifth region, default is immediate in both states, and so $q_{U, 11}=q_{U, 12}=q_{U, 21}=q_{U, 22}=0$. Therefore, in summary we have (B3), where the 16 constants, $g_{11,1}, g_{11,2}, h_{11,1}, h_{11,2}, h_{11,3}, h_{11,4}, g_{12,1}, g_{12,2}, h_{12,1}, h_{12,2}, h_{12,3}, h_{12,4}, s_{11,1}, s_{11,2}$, $s_{12,1}, s_{12,2}$, are the solutions of the 16 simultaneous linear equations, which arise from the 16 boundary conditions:

$$
\begin{aligned}
& \left.q_{U, 11}\right|_{X \downarrow X_{U, 1}}=\left.q_{U, 11}\right|_{X \uparrow X_{U, 1}},\left.q_{U, 21}\right|_{X \downarrow X_{U, 2}}=\left.q_{U, 21}\right|_{X \uparrow X_{U, 2}},\left.q_{U, 11}\right|_{X \downarrow X_{D}, 1}=\left.q_{U, 11}\right|_{X \uparrow X_{D, 1}},\left.q_{U, 21}\right|_{X \downarrow X_{D, 2}}=\left.q_{U, 21}\right|_{X \uparrow X_{D, 2}}, \\
& \left.q_{U, 11}\right|_{X \downarrow X_{U, 2}}=\left.q_{U, 11}\right|_{X \uparrow X_{U, 2}},\left.q_{U, 11}^{\prime}\right|_{X \downarrow X_{U, 2}}=\left.q_{U, 11}^{\prime}\right|_{X \uparrow X_{U, 2}},\left.q_{U, 21}\right|_{X \downarrow X_{D}, 1}=\left.q_{U, 21}\right|_{X \uparrow X_{D, 1}},\left.q_{U, 21}^{\prime}\right|_{X \downarrow X_{D, 1}}=\left.q_{U, 21}^{\prime}\right|_{X \uparrow X_{D, 1}}, \\
& \left.q_{U, 12}\right|_{X \downarrow X_{U, 1}}=\left.q_{U, 12}\right|_{X \uparrow X_{U, 1}},\left.q_{U, 22}\right|_{X \downarrow X_{U, 2}}=\left.q_{U, 22}\right|_{X \uparrow X_{U, 2}},\left.q_{U, 12}\right|_{X \downarrow X_{D, 1}}=\left.q_{U, 12}\right|_{X \uparrow X_{D, 1}},\left.q_{U, 22}\right|_{X \downarrow X_{D, 2}}=\left.q_{U, 22}\right|_{X \uparrow X_{D, 2}}, \\
& \left.q_{U, 12}\right|_{X \downarrow X_{U, 2}}=\left.q_{U, 12}\right|_{X \uparrow X_{U, 2}},\left.q_{U, 12}^{\prime}\right|_{X \downarrow X_{U, 2}}=\left.q_{U, 12}^{\prime}\right|_{X \uparrow X_{U, 2}},\left.q_{U, 22}\right|_{X \downarrow X_{D}, 1}=\left.q_{U, 22}\right|_{X \uparrow X_{D, 1}},\left.q_{U, 22}^{\prime}\right|_{X \downarrow X_{D, 1}}=\left.q_{U, 22}^{\prime}\right|_{X \uparrow X_{D, 1}} .
\end{aligned}
$$

We now solve for the Arrow-Debreu default claim. The time- $t$ price of the perpetual Arrow-Debreu default claim which pays out a unit of consumption at default if default occurs in state $j$, conditional on the current state being $i$ satisfies the basic asset pricing equation

$$
E_{t}^{\mathbb{Q}}\left[d q_{D, i j}-r_{i} q_{D, i j} d t \mid \nu_{t}=i\right]
$$

Therefore,

$$
\frac{1}{2} X^{2} \sigma_{X, i}^{2} \frac{d^{2} q_{D, i j}}{d X^{2}}+X \hat{\theta}_{i} \frac{d q_{D, i j}}{d X}+\widehat{\lambda}_{i}\left(q_{D, k j}-q_{D, i j}\right)-r_{i} q_{D, i j}=0
$$

subject to relevant boundary conditions. In the first region, refinancing is immediate whatever the current state is. Therefore $q_{D, 11}=q_{D, 12}=q_{D, 21}=q_{D, 22}$. In the second region, refinancing is immediate if the current state is 2 . Therefore, $q_{D, 21}=$ $q_{D, 22}=0$. To find $q_{D, 11}$ and $q_{D, 12}$, we must solve the ordinary differential equations

$$
\frac{1}{2} X^{2} \sigma_{X, 1}^{2} \frac{d^{2} q_{D, 1 j}}{d X^{2}}+X \hat{\theta}_{1} \frac{d q_{D, 1 j}}{d X}-\left(r_{1}+\widehat{\lambda}_{1}\right) q_{D, 1 j}=0
$$

The general solutions of the above equations are

$$
\begin{aligned}
& q_{D, 11}=\sum_{m=1}^{2} g_{11, m} X^{l_{m}}, \\
& q_{D, 12}=\sum_{m=1}^{2} g_{12, m} X^{l_{m}} .
\end{aligned}
$$

In the third region,

$$
\left(\frac{1}{2}\left[\begin{array}{cc}
\sigma_{X, 1}^{2} & 0 \\
0 & \sigma_{X, 2}^{2}
\end{array}\right] X^{2} \frac{d^{2}}{d X^{2}}+\left[\begin{array}{cc}
\widehat{\theta}_{1} & 0 \\
0 & \widehat{\theta}_{2}
\end{array}\right] X \frac{d}{d X}-\left[\begin{array}{cc}
r_{1} & 0 \\
0 & r_{2}
\end{array}\right]+\left[\begin{array}{cc}
-\widehat{\lambda}_{1} & \widehat{\lambda}_{1} \\
\widehat{\lambda}_{2} & -\widehat{\lambda}_{2}
\end{array}\right]\right)\left[\begin{array}{cc}
q_{D, 11} & q_{D, 12} \\
q_{D}, 21 & q_{D, 22}
\end{array}\right]=\left[\begin{array}{ll}
0 & 0 \\
0 & 0
\end{array}\right] .
$$

The above ordinary differential equation system has the following general solution

$$
\begin{aligned}
q_{D, 1 j} & =\sum_{m=1}^{4} h_{1 j, m} X^{k_{m}}, \\
q_{D, 2 j} & =\sum_{m=1}^{4} \epsilon\left(k_{m}\right) h_{1 j, m} X^{k_{m}} .
\end{aligned}
$$


In the fourth region default is immediate if the state is 1 , but not if the state is 2 . Therefore, $q_{D, 11}=1$ and $q_{D, 12}=0$. Also,

$$
\frac{1}{2} X^{2} \sigma_{X, 2}^{2} \frac{d^{2} q_{D, 21}}{d X^{2}}+X \hat{\theta}_{2} \frac{d q_{D, 21}}{d X}+\widehat{\lambda}_{2}\left(1-q_{D, 21}\right)-r_{2} q_{D, 21}=0
$$

and

$$
\frac{1}{2} X^{2} \sigma_{X, 2}^{2} \frac{d^{2} q_{D, 22}}{d X^{2}}+X \hat{\theta}_{2} \frac{d q_{D, 22}}{d X}+\widehat{\lambda}_{2}\left(0-q_{D, 22}\right)-r_{2} q_{D, 22}=0
$$

Therefore,

$$
\left(\frac{1}{2} \sigma_{X, 2}^{2}\left[\begin{array}{ll}
1 & 0 \\
0 & 1
\end{array}\right] \frac{d^{2}}{d X^{2}}+\widehat{\theta}_{2}\left[\begin{array}{ll}
1 & 0 \\
0 & 1
\end{array}\right] \frac{d}{d X}-\left(\widehat{\lambda}_{2}+r_{2}\right)\left[\begin{array}{cc}
1 & 0 \\
0 & 1
\end{array}\right]\right)\left[\begin{array}{c}
q_{D, 21} \\
q_{D, 22}
\end{array}\right]+\left[\begin{array}{c}
\hat{\lambda}_{2} \\
0
\end{array}\right]=\underline{0}
$$

The general solutions of the above ordinary differential equations are

$$
\begin{aligned}
q_{D, 21} & =s_{11,1} X^{j_{1}}+s_{11,2} X^{j_{2}}+\frac{\widehat{\lambda}_{2}}{r_{2}+\widehat{\lambda}_{2}} \\
q_{D, 22} & =s_{12,1} X^{j_{1}}+s_{12,2} X^{j_{2}}
\end{aligned}
$$

Therefore, in summary we have (B4). To determine the 16 constants, $g_{11,1}, g_{11,2}, h_{11,1}, h_{11,2}, h_{11,3}, h_{11,4}, g_{12,1}, g_{12,2}, h_{12,1}$, $h_{12,2}, h_{12,3}, h_{12,4}, s_{11,1}, s_{11,2}, s_{12,1}, s_{12,2}$, we solve 16 simultaneous linear equations, which arise from the 16 boundary conditions:

$$
\begin{aligned}
& \left.q_{D, 11}\right|_{X \downarrow X_{U, 1}}=\left.q_{D, 11}\right|_{X \uparrow X_{U, 1}},\left.q_{D, 21}\right|_{X \downarrow X_{U, 2}}=\left.q_{D, 21}\right|_{X \uparrow X_{U, 2}},\left.q_{D, 11}\right|_{X \downarrow X_{D, 1}}=\left.q_{D, 11}\right|_{X \uparrow X_{D, 1}},\left.q_{D, 21}\right|_{X \downarrow X_{D, 2}}=\left.q_{D, 21}\right|_{X \uparrow X_{D, 2}}, \\
& \left.q_{D, 11}\right|_{X \downarrow X_{U, 2}}=\left.q_{D, 11}\right|_{X \uparrow X_{U, 2}},\left.q_{D, 11}^{\prime}\right|_{X \downarrow X_{U, 2}}=\left.q_{D, 11}^{\prime}\right|_{X \uparrow X_{U, 2}},\left.q_{D, 21}\right|_{X \downarrow X_{D, 1}}=\left.q_{D, 21}\right|_{X \uparrow X_{D, 1}},\left.q_{D, 21}^{\prime}\right|_{X \downarrow X_{D, 1}}=\left.q_{D, 21}^{\prime}\right|_{X \uparrow X_{D, 1}}, \\
& \left.q_{D, 12}\right|_{X \downarrow X_{U, 1}}=\left.q_{D, 12}\right|_{X \uparrow X_{U, 1}},\left.q_{D, 22}\right|_{X \downarrow X_{U, 2}}=\left.q_{D, 22}\right|_{X \uparrow X_{U, 2}},\left.q_{D, 12}\right|_{X \downarrow X_{D, 1}}=\left.q_{D, 12}\right|_{X \uparrow X_{D, 1}},\left.q_{D, 22}\right|_{X \downarrow X_{D, 2}}=\left.q_{D, 22}\right|_{X \uparrow X_{D, 2}}, \\
& \left.q_{D, 12}\right|_{X \downarrow X_{U, 2}}=\left.q_{D, 12}\right|_{X \uparrow X_{U, 2}},\left.q_{D, 12}^{\prime}\right|_{X \downarrow X_{U, 2}}=\left.q_{D, 12}^{\prime}\right|_{X \uparrow X_{U, 2}},\left.q_{D, 22}\right|_{X \downarrow X_{D, 1}}=\left.q_{D, 22}\right|_{X \uparrow X_{D, 1}},\left.q_{D, 22}^{\prime}\right|_{X \downarrow X_{D, 1}}=\left.q_{D, 22}^{\prime}\right|_{X \uparrow X_{D, 1}} .
\end{aligned}
$$

When $X_{U, 1}<X_{U, 2}$, we must solve for Arrow-Debreu default and refinancing claims in the following 5 regions: $1 . X>X_{U, 2}$; 2. $X_{U, 1} \leq X \leq X_{U, 2}$; 3. $X_{D, 1} \leq X \leq X_{U, 1} ; 4$. $X_{D, 2} \leq X \leq X_{D, 1} ; 5 . X \leq X_{D, 2}$.

In the first of the above regions, refinancing is immediate whatever the current state is. Therefore, $q_{U, 11}=q_{U, 22}=1$ and $q_{U, 12}=q_{U, 21}=0$. In the second region, refinancing is immediate when the state is 1 , but not when the state is 2 . Therefore, $q_{U, 11}=0, q_{U, 12}=0$ and

$$
\begin{aligned}
& \frac{1}{2} X^{2} \sigma_{X, 2}^{2} \frac{d^{2} q_{U, 21}}{d X^{2}}+X \hat{\theta}_{1} \frac{d q_{U, 21}}{d X}+\widehat{\lambda}_{2}\left(1-q_{U, 21}\right)-r_{1} q_{U, 21}=0 \\
& \frac{1}{2} X^{2} \sigma_{X, 2}^{2} \frac{d^{2} q_{U, 22}}{d X^{2}}+X \hat{\theta}_{1} \frac{d q_{U, 22}}{d X}+\widehat{\lambda}_{2}\left(0-q_{U, 22}\right)-r_{1} q_{U, 22}=0 .
\end{aligned}
$$

Therefore,

$$
\left(\frac{1}{2} \sigma_{X, 2}^{2}\left[\begin{array}{ll}
1 & 0 \\
0 & 1
\end{array}\right] \frac{d^{2}}{d X^{2}}+\widehat{\theta}_{2}\left[\begin{array}{ll}
1 & 0 \\
0 & 1
\end{array}\right] \frac{d}{d X}-\left(\hat{\lambda}_{2}+r_{2}\right)\left[\begin{array}{ll}
1 & 0 \\
0 & 1
\end{array}\right]\right)\left[\begin{array}{c}
q_{U, 21} \\
q_{U, 22}
\end{array}\right]+\left[\begin{array}{c}
\hat{\lambda}_{2} \\
0
\end{array}\right]=\underline{0} .
$$

The general solutions of the above ode's are

$$
\begin{aligned}
q_{U, 21} & =g_{11,1} X^{j_{1}}+g_{11,2} X^{j_{2}}+\frac{\widehat{\lambda}_{2}}{r_{2}+\widehat{\lambda}_{2}} \\
q_{U, 22} & =g_{12,1} X^{j_{1}}+g_{12,2} X^{j_{2}}
\end{aligned}
$$


In the third region

$$
\left(\frac{1}{2}\left[\begin{array}{cc}
\sigma_{X, 1}^{2} & 0 \\
0 & \sigma_{X, 2}^{2}
\end{array}\right] X^{2} \frac{d^{2}}{d X^{2}}+\left[\begin{array}{cc}
\widehat{\theta}_{1} & 0 \\
0 & \widehat{\theta}_{2}
\end{array}\right] X \frac{d}{d X}-\left[\begin{array}{cc}
r_{1} & 0 \\
0 & r_{2}
\end{array}\right]+\left[\begin{array}{cc}
-\widehat{\lambda}_{1} & \widehat{\lambda}_{1} \\
\widehat{\lambda}_{2} & -\widehat{\lambda}_{2}
\end{array}\right]\right)\left[\begin{array}{ccc}
q_{U, 11} & q_{U, 12} \\
q_{U, 21} & q_{U, 22}
\end{array}\right]=\left[\begin{array}{ll}
0 & 0 \\
0 & 0
\end{array}\right]
$$

The above ordinary differential equation system has the following general solution

$$
\begin{aligned}
q_{U, 1 j} & =\sum_{m=1}^{4} h_{1 j, m} X^{k_{m}} \\
q_{U, 2 j} & =\sum_{m=1}^{4} \epsilon\left(k_{m}\right) h_{1 j, m} X^{k_{m}} .
\end{aligned}
$$

In the fourth region default is immediate if the state is 1 , but not if the state is 2 . Therefore, $q_{U, 11}=q_{U, 12}=0$ and

$$
\frac{1}{2} X^{2} \sigma_{X, 2}^{2} \frac{d^{2} q_{U, 2 j}}{d X^{2}}+X \hat{\theta}_{2} \frac{d q_{U, 2 j}}{d X}-\left(r_{2}+\widehat{\lambda}_{2}\right) q_{U, 2 j}=0
$$

The general solution of the above ode is

$$
q_{U, 2 j}=\sum_{m=1}^{2} s_{2 j, m} X^{j_{m}} .
$$

In summary, we have (B5). To determine the 16 constants, $g_{11,1}, g_{11,2}, h_{11,1}, h_{11,2}, h_{11,3}, h_{11,4}, g_{12,1}, g_{12,2}, h_{12,1}, h_{12,2}$, $h_{12,3}, h_{12,4}, s_{11,1}, s_{11,2}, s_{12,1}, s_{12,2}$, we solve 16 simultaneous linear equations, which arise from the 16 boundary conditions:

$$
\begin{gathered}
\left.q_{U, 11}\right|_{X \downarrow X_{U, 1}}=\left.q_{U, 11}\right|_{X \uparrow X_{U, 1}},\left.q_{U, 11}\right|_{X \downarrow X_{D, 1}}=\left.q_{U, 11}\right|_{X \uparrow X_{D, 1}},\left.q_{U, 21}\right|_{X \downarrow X_{U, 2}}=\left.q_{U, 21}\right|_{X \uparrow X_{U, 2}},\left.q_{U, 21}\right|_{X \downarrow X_{U, 1}}=\left.q_{U, 21}\right|_{X \uparrow X_{U, 1}}, \\
\left.q_{U, 21}\right|_{X \downarrow X_{D, 1}}=\left.q_{U, 21}\right|_{X \uparrow X_{D, 1}},\left.q_{U, 21}\right|_{X \downarrow X_{D, 2}}=\left.q_{U, 21}\right|_{X \uparrow X_{D, 2}},\left.q_{U, 21}^{\prime}\right|_{X \downarrow X_{U, 1}}=\left.q_{U, 21}^{\prime}\right|_{X \uparrow X_{U, 1}},\left.q_{U, 21}^{\prime}\right|_{X \downarrow X_{D, 1}}=\left.q_{U, 21}^{\prime}\right|_{X \uparrow X_{D, 1}}, \\
\left.q_{U, 12}\right|_{X \downarrow X_{U, 1}}=\left.q_{U, 12}\right|_{X \uparrow X_{U, 1}},\left.q_{U, 12}\right|_{X \downarrow X_{D, 1}}=\left.q_{U, 12}\right|_{X \uparrow X_{D, 1}},\left.q_{U, 22}\right|_{X \downarrow X_{U, 2}}=\left.q_{U, 22}\right|_{X \uparrow X_{U, 2}},\left.q_{U, 22}\right|_{X \downarrow X_{U, 1}}=\left.q_{U, 22}\right|_{X \uparrow X_{U, 1}}, \\
\left.q_{U, 22}\right|_{X \downarrow X_{D, 1}}=\left.q_{U, 22}\right|_{X \uparrow X_{D, 1}},\left.q_{U, 22}\right|_{X \downarrow X_{D, 2}}=\left.q_{U, 22}\right|_{X \uparrow X_{D, 2}},\left.q_{U, 22}^{\prime}\right|_{X \downarrow X_{U, 1}}=\left.q_{U, 22}^{\prime}\right|_{X \uparrow X_{U, 1}},\left.q_{U, 22}^{\prime}\right|_{X \downarrow X_{D, 1}}=\left.q_{U, 22}^{\prime}\right|_{X \uparrow X_{D, 1}} .
\end{gathered}
$$

We now solve for Arrow-Debreu default claims. In the first region, refinancing is immediate whatever the current state is. Therefore, $q_{D, 11}=q_{D, 12}=q_{D, 21}=q_{D, 22}=0$. In the second region, refinancing is immediate when the state is 1 , but not when the state is 2 . Therefore, $q_{D, 11}=q_{D, 12}=0$ and

$$
\begin{aligned}
& \frac{1}{2} X^{2} \sigma_{X, 2}^{2} \frac{d^{2} q_{D, 21}}{d X^{2}}+X \hat{\theta}_{1} \frac{d q_{D, 21}}{d X}+\widehat{\lambda}_{2}\left(0-q_{D, 21}\right)-r_{1} q_{D, 21}=0 \\
& \frac{1}{2} X^{2} \sigma_{X, 2}^{2} \frac{d^{2} q_{D, 22}}{d X^{2}}+X \hat{\theta}_{1} \frac{d q_{D, 22}}{d X}+\widehat{\lambda}_{2}\left(0-q_{D, 22}\right)-r_{1} q_{D, 22}=0
\end{aligned}
$$

Therefore,

$$
\left(\frac{1}{2} \sigma_{X, 2}^{2}\left[\begin{array}{ll}
1 & 0 \\
0 & 1
\end{array}\right] \frac{d^{2}}{d X^{2}}+\widehat{\theta}_{2}\left[\begin{array}{ll}
1 & 0 \\
0 & 1
\end{array}\right] \frac{d}{d X}-\left(\widehat{\lambda}_{2}+r_{2}\right)\left[\begin{array}{ll}
1 & 0 \\
0 & 1
\end{array}\right]\right)\left[\begin{array}{l}
q_{D, 21} \\
q_{D, 22}
\end{array}\right]=\left[\begin{array}{l}
0 \\
0
\end{array}\right] .
$$

The general solutions of the above ordinary differential equations are

$$
\begin{aligned}
& q_{D, 21}=g_{11,1} X^{j_{1}}+g_{11,2} X^{j_{2}} \\
& q_{D, 22}=g_{12,1} X^{j_{1}}+g_{12,2} X^{j_{2}} .
\end{aligned}
$$


In the third region

$$
\left(\frac{1}{2}\left[\begin{array}{cc}
\sigma_{X, 1}^{2} & 0 \\
0 & \sigma_{X, 2}^{2}
\end{array}\right] X^{2} \frac{d^{2}}{d X^{2}}+\left[\begin{array}{cc}
\widehat{\theta}_{1} & 0 \\
0 & \widehat{\theta}_{2}
\end{array}\right] X \frac{d}{d X}-\left[\begin{array}{cc}
r_{1} & 0 \\
0 & r_{2}
\end{array}\right]+\left[\begin{array}{cc}
-\widehat{\lambda}_{1} & \widehat{\lambda}_{1} \\
\widehat{\lambda}_{2} & -\widehat{\lambda}_{2}
\end{array}\right]\right)\left[\begin{array}{cc}
q_{D, 11} & q_{D, 12} \\
q_{D}, 21 & q_{D, 22}
\end{array}\right]=\left[\begin{array}{ll}
0 & 0 \\
0 & 0
\end{array}\right]
$$

The above ordinary differential equation system has the following general solution

$$
\begin{aligned}
q_{D, 1 j} & =\sum_{m=1}^{4} h_{1 j, m} X^{k_{m}}, \\
q_{D, 2 j} & =\sum_{m=1}^{4} \epsilon\left(k_{m}\right) h_{1 j, m} X^{k_{m}} .
\end{aligned}
$$

In the fourth region default is immediate if the state is 1 , but not if the state is 2 . Therefore, $q_{D, 11}=1$ and $q_{D, 12}=0$, and so

$$
\begin{aligned}
& \frac{1}{2} X^{2} \sigma_{X, 2}^{2} \frac{d^{2} q_{D, 21}}{d X^{2}}+X \hat{\theta}_{2} \frac{d q_{D, 21}}{d X}+\widehat{\lambda}_{2}\left(1-q_{D, 21}\right)-r_{2} q_{D, 21}=0 \\
& \frac{1}{2} X^{2} \sigma_{X, 2}^{2} \frac{d^{2} q_{D, 22}}{d X^{2}}+X \hat{\theta}_{2} \frac{d q_{D, 22}}{d X}+\widehat{\lambda}_{2}\left(0-q_{D, 22}\right)-r_{2} q_{D, 22}=0
\end{aligned}
$$

The general solutions of the above ordinary differential equations are

$$
\begin{aligned}
q_{D, 21} & =\sum_{m=1}^{2} s_{22, m} X^{j_{m}}+\frac{\widehat{\lambda}_{2}}{r_{2}+\widehat{\lambda}_{2}}, \\
q_{D, 22} & =\sum_{m=1}^{2} s_{22, m} X^{j_{m}} .
\end{aligned}
$$

In summary, we have (B6). To determine the 16 constants, $g_{11,1}, g_{11,2}, h_{11,1}, h_{11,2}, h_{11,3}, h_{11,4}, g_{12,1}, g_{12,2}, h_{12,1}, h_{12,2}$, $h_{12,3}, h_{12,4}, s_{11,1}, s_{11,2}, s_{12,1}, s_{12,2}$, we solve 16 simultaneous linear equations, which arise from the 16 boundary conditions:

$$
\begin{gathered}
\left.q_{D, 11}\right|_{X \downarrow X_{U, 1}}=\left.q_{D, 11}\right|_{X \uparrow X_{U, 1}},\left.q_{D, 11}\right|_{X \downarrow X_{D, 1}}=\left.q_{D, 11}\right|_{X \uparrow X_{D, 1}},\left.q_{D, 21}\right|_{X \downarrow X_{U, 2}}=\left.q_{D, 21}\right|_{X \uparrow X_{U, 2}},\left.q_{D, 21}\right|_{X \downarrow X_{U, 1}}=\left.q_{D, 21}\right|_{X \uparrow X_{U, 1}}, \\
\left.q_{D, 21}\right|_{X \downarrow X_{D, 1}}=\left.q_{D, 21}\right|_{X \uparrow X_{D, 1}},\left.q_{D, 21}\right|_{X \downarrow X_{D, 2}}=\left.q_{D, 21}\right|_{X \uparrow X_{D, 2}},\left.q_{D, 21}^{\prime}\right|_{X \downarrow X_{U, 1}}=\left.q_{D, 21}^{\prime}\right|_{X \uparrow X_{U, 1}},\left.q_{D, 21}^{\prime}\right|_{X \downarrow X_{D, 1}}=\left.q_{D, 21}^{\prime}\right|_{X \uparrow X_{D, 1}}, \\
\left.q_{D, 12}\right|_{X \downarrow X_{U, 1}}=\left.q_{D, 12}\right|_{X \uparrow X_{U, 1}},\left.q_{D, 12}\right|_{X \downarrow X_{D, 1}}=\left.q_{D, 12}\right|_{X \uparrow X_{D, 1}},\left.q_{D, 22}\right|_{X \downarrow X_{U, 2}}=\left.q_{D, 22}\right|_{X \uparrow X_{U, 2}},\left.q_{D, 22}\right|_{X \downarrow X_{U, 1}}=\left.q_{D, 22}\right|_{X \uparrow X_{U, 1}}, \\
\left.q_{D, 22}\right|_{X \downarrow X_{D, 1}}=\left.q_{D, 22}\right|_{X \uparrow X_{D, 1}},\left.q_{D, 22}\right|_{X \downarrow X_{D, 2}}=\left.q_{D, 22}\right|_{X \uparrow X_{D, 2}},\left.q_{D, 22}^{\prime}\right|_{X \downarrow X_{U, 1}}=\left.q_{D, 22}^{\prime}\right|_{X \uparrow X_{U, 1}},\left.q_{D, 22}^{\prime}\right|_{X \downarrow X_{D, 1}}=\left.q_{D, 22}^{\prime}\right|_{X \uparrow X_{D, 1}} .
\end{gathered}
$$

Proof of Proposition 3. For ease of notation, we define $\xi_{\nu_{0}, \nu_{U}}=\xi_{\nu_{U}}\left(c_{\nu_{0}}\right)$. At refinancing existing debt is diluted on a per coupon basis, so that (23) holds. Note that

$$
c_{\nu_{U}}\left(c_{\nu_{0}}\right)=c_{\nu_{U}} \frac{X_{U, \nu_{0}, \nu_{U}}}{X_{0}}=c_{\nu_{U}} \xi_{\nu_{0}, \nu_{U}}
$$

Therefore,

$$
B_{\nu_{U}}\left(X_{U, \nu_{0}, \nu_{U}}, c_{\nu_{U}}\left(c_{\nu_{0}}\right), \nu_{U}\right)=B_{\nu_{U}}\left(\xi_{\nu_{0}, \nu_{U}} X_{0}, \xi_{\nu_{0}, \nu_{U}} c_{\nu_{U}}, \nu_{U}\right)
$$

which can be simplified using the homogeneity property to give

$$
B_{\nu_{U}}\left(X_{U, \nu_{0}, \nu_{U}}, c_{\nu_{U}}\left(c_{\nu_{0}}\right), \nu_{U}\right)=\xi_{\nu_{0}, \nu_{U}} B_{\nu_{U}}\left(X_{0}, c_{\nu_{U}}, \nu_{U}\right) .
$$


It then follows from (23) that

$$
R_{\nu_{0}, \nu_{U}}\left(X_{U, \nu_{0}, \nu_{U}}, c_{\nu_{0}}, c_{\nu_{U}}\left(c_{\nu_{0}}\right)\right)=\frac{c_{\nu_{0}}}{c_{\nu_{U}}} B_{\nu_{U}}\left(X_{0}, c_{\nu_{U}}, \nu_{U}\right)
$$

Thus (21) implies that

$$
\begin{aligned}
B_{\nu_{t}}\left(X_{t}, c_{\nu_{0}}, \nu_{0}\right)= & \frac{c_{\nu_{0}}}{r_{P, \nu_{t}}}+\sum_{\nu_{D}=1}^{2} q_{D, \nu_{t} \nu_{D}}\left(X_{t}, \nu_{0}\right)\left(\alpha_{\nu_{D}} A_{\nu_{D}}\left(X_{D, \nu_{0} \nu_{D}}\right)-\frac{c_{\nu_{0}}}{r_{P, \nu_{D}}}\right) \\
& +c_{\nu_{0}} \sum_{\nu_{D}=1}^{2} q_{U, \nu_{t} \nu_{D}}\left(X_{t}, \nu_{0}\right)\left(\frac{B_{\nu_{D}}\left(X_{0}, c_{\nu_{D}}, \nu_{D}\right)}{c_{\nu_{D}}}-\frac{1}{r_{P, \nu_{D}}}\right) .
\end{aligned}
$$

Evaluating the above expression at, $X_{t}=X_{0}$, gives debt values at refinancing:

$$
\begin{aligned}
B_{\nu_{0}}\left(X_{0}, c_{\nu_{0}}, \nu_{0}\right)= & \frac{c_{\nu_{0}}}{r_{P, \nu_{0}}}+\sum_{\nu_{D}=1}^{2} q_{D, \nu_{0} \nu_{D}}\left(X_{0}, \nu_{0}\right)\left(\alpha_{\nu_{D}} A_{\nu_{D}}\left(X_{D, \nu_{0} \nu_{D}}\right)-\frac{c_{\nu_{0}}}{r_{P, \nu_{D}}}\right) \\
& +c_{\nu_{0}} \sum_{\nu_{D}=1}^{2} q_{U, \nu_{0} \nu_{D}}\left(X_{t}, \nu_{0}\right)\left(\frac{B_{\nu_{D}}\left(X_{0}, c_{\nu_{D}}, \nu_{D}\right)}{c_{\nu_{D}}}-\frac{1}{r_{P, \nu_{D}}}\right) .
\end{aligned}
$$

Since $\nu_{0} \in\{1,2\}$, we obtain the following matrix equation

$$
\left(\begin{array}{cc}
1-q_{U, 11}\left(X_{0}, 1\right) & -\frac{c_{1}}{c_{2}} q_{U, 12}\left(X_{0}, 1\right) \\
-\frac{c_{2}}{c_{1}} q_{U, 21}\left(X_{0}, 2\right) & 1-q_{U, 22}\left(X_{0}, 2\right)
\end{array}\right)\left(\begin{array}{c}
B_{1}\left(X_{0}, c_{1}, 1\right) \\
B_{2}\left(X_{0}, c_{2}, 2\right)
\end{array}\right)=\left(\begin{array}{c}
b_{1}\left(X_{0}, c_{1}\right) \\
b_{2}\left(X_{0}, c_{2}\right)
\end{array}\right)
$$

where $b_{i}\left(X_{0}, c_{i}\right), i \in\{1,2\}$ are defined by

$$
b_{i}\left(X_{0}, c_{i}\right)=\frac{c_{i}}{r_{P, i}}\left(1-\sum_{\nu_{D}=1}^{2} q_{D, i \nu_{D}}\left(X_{0}, i\right) l_{D, \nu_{D}}-\sum_{\nu_{U}=1}^{2} q_{U, \nu_{U}}\left(X_{0}, i\right) \frac{r_{P, i}}{r_{P, \nu_{U}}}\right), i \in\{1,2\}
$$

and $l_{D, i \nu_{D}}$ is defined in (25). Solving the above matrix equation gives us

$$
B_{i}\left(X_{0}, c_{i}, i\right)=\Delta_{B}^{-1}\left[\left(1-q_{U, j j}\left(X_{0}, X_{D, j j}\right)\right) b_{i}\left(X_{0}, c_{i}\right)+\frac{c_{i}}{c_{j}} q_{U, i j}\left(X_{0}, X_{D, i j}\right) b_{j}\left(X_{0}, c_{j}\right)\right], j \neq i
$$

where $\Delta_{B}=\left(1-q_{U, 11}\left(X_{0}, 1\right)\right)\left(1-q_{U, 22}\left(X_{0}, 2\right)\right)-q_{U, 21}\left(X_{0}, 2\right) q_{U, 12}\left(X_{0}, 1\right)$. Thus, we can use (B13) to compute $B_{\nu_{t}}\left(X_{t}, c_{\nu_{0}}, \nu_{0}\right)$, where the current state is not necessarily the same as the state at refinancing. Note that the expression for $B_{\nu_{t}}\left(X_{t}, c_{\nu_{0}}, \nu_{0}\right)$ in (B13) can be rewritten as (24).

Proof of Proposition 4. For ease of notation, we define $\xi_{\nu_{0}, \nu_{U}}=\xi_{\nu_{U}}\left(c_{\nu_{0}}\right)$. If refinancing occurs in state $j$, the value of equity just before refinancing is given by (28). Since the homogeneity property implies that (B11), (B12), and

$$
S_{j}\left(X_{U, \nu_{0} j}, c_{j}\left(c_{\nu_{0}}\right), j\right)=S_{j}\left(\xi_{\nu_{0}, j} X_{0}, \xi_{\nu_{0}, j} c_{j}, j\right)=\xi_{\nu_{0}, j} S_{j}\left(X_{0}, c_{j}, j\right)
$$

it follows that

$$
E_{\nu_{0}, j}\left(X_{U, \nu_{0} j}\right)=B_{j}\left(X_{0}, c_{j}, j\right)\left(\left(1-\iota_{j}\right) \xi_{\nu_{0}, j}-\frac{c_{\nu_{0}}}{c_{j}}\right)+\xi_{\nu_{0}, j} S_{j}\left(X_{0}, c_{j}, j\right)
$$

Hence,

$$
S_{\nu_{t}}\left(X_{t}, c_{\nu_{0}}, \nu_{0}\right)=\operatorname{Div}_{\nu_{t}}\left(X_{t}, c_{\nu_{0}}, \nu_{0}\right)+\sum_{j=1}^{2} q_{U, \nu_{t} j}\left(X_{t}, \nu_{0}\right)\left[B_{j}\left(X_{0}, c_{j}, j\right)\left(\left(1-\iota_{j}\right) \xi_{\nu_{0}, j}-\frac{c_{\nu_{0}}}{c_{j}}\right)+\xi_{\nu_{0}, j} S_{j}\left(X_{0}, c_{j}, j\right)\right]
$$


Evaluating the above expression at $X_{t}=X_{0}$ gives equity values at refinancing:

$$
S_{\nu_{0}}\left(X_{0}, c_{\nu_{0}}, \nu_{0}\right)=\operatorname{Div}_{\nu_{0}}\left(X_{0}, c_{\nu_{0}}, \nu_{0}\right)+\sum_{j=1}^{2} q_{U, \nu_{0} j}\left(X_{0}, \nu_{0}\right)\left[B_{j}\left(X_{0}, c_{j}, j\right)\left(\left(1-\iota_{j}\right) \xi_{\nu_{0}, j}-\frac{c_{\nu_{0}}}{c_{j}}\right)+\xi_{\nu_{0}, j} S_{j}\left(X_{0}, c_{j}, j\right)\right]
$$

Since $\nu_{0} \in\{1,2\}$, we obtain the following matrix equation

$$
\left(\begin{array}{cc}
1-q_{U, 11}\left(X_{0}, 1\right) \xi_{11} & -q_{U, 12}\left(X_{0}, 1\right) \xi_{12} \\
-q_{U, 21}\left(X_{0}, 2\right) \xi_{21} & 1-q_{U, 22}\left(X_{0}, 2\right) \xi_{22}
\end{array}\right)\left(\begin{array}{c}
S_{1}\left(X_{0}, c_{1}, 1\right) \\
S_{2}\left(X_{0}, c_{2}, 2\right)
\end{array}\right)=\left(\begin{array}{c}
s_{1}\left(X_{0}, c_{1}\right) \\
s_{2}\left(X_{0}, c_{2}\right)
\end{array}\right)
$$

where $s_{i}\left(X_{0}, c_{i}\right), i \in\{1,2\}$ are defined by

$$
s_{i}\left(X_{0}, c_{i}\right)=\operatorname{Div}_{i}\left(X_{0}, c_{i}, i\right)+\sum_{j=\nu_{U}}^{2} q_{U, i \nu_{U}} B_{\nu_{U}}\left(X_{0}, c_{\nu_{U}}, \nu_{U}\right)\left(\left(1-\iota_{\nu_{U}}\right) \xi_{1 \nu_{U}}-\frac{c_{i}}{c_{\nu_{U}}}\right)
$$

Solving the above matrix equation gives

$$
S_{i}\left(X_{0}, c_{i}, i\right)=\Delta_{S}^{-1}\left[\left(1-q_{U, j j}\left(X_{0}, j\right)\right) \xi_{j j} s_{i}\left(X_{0}, c_{i}\right)+q_{U, i j}\left(X_{0}, i\right) \xi_{i j} s_{j}\left(X_{0}, c_{j}\right)\right], j \neq i,
$$

where $\Delta_{S}=\left(1-q_{U, 11}\left(X_{0}, 1\right) \xi_{11}\right)\left(1-q_{U, 22}\left(X_{0}, 2\right) \xi_{22}\right)-q_{U, 12}\left(X_{0}, 1\right) q_{U, 21}\left(X_{0}, 2\right) \xi_{21} \xi_{12}$. Using the above solution, we can exploit (B16) to rewrite $S_{\nu_{t}}\left(X_{t}, c_{\nu_{0}}, \nu_{0}\right)$ as (29).

Proof of Proposition 5. It is clear that $S_{1}(X) \leq S_{2}(X)$ and that both $S_{1}(X)$ and $S_{2}(X)$ are monotonically increasing in $X$. Thus, for $i \in\{1,2\}$, if there exists $X_{D, i}$ such that $S_{i}\left(X_{D, i}\right)=0$, then $X_{D, i}$ is unique. From $S_{1}(X) \leq S_{2}(X)$ it follows that $S_{2}\left(X_{D, 1}\right) \geq S_{1}\left(X_{D, 1}\right)=0$. Since $S_{2}(X)$ is monotonically increasing in $X$, it follows that $X_{D, 2} \leq X_{D, 1}$.

\section{References}

Acharya, Viral V., Sreedhar T. Bharath, and Anand Srinivasan, 2007, Does Industry-wide Distress Affect Defaulted Firms? Evidence from Creditor Recoveries, Journal of Financial Economics 85, 787-821.

Almeida, Heitor, and Murillo Campello, 2007, Financial Constraints, Asset Tangibility, and Corporate Investment, Review of Financial Studies 20, 1429-1460.

Almeida, Heitor, Murillo Campello, and Michael S. Weisbach, 2005, The Cash Flow Sensitivity of Cash, Journal of Finance 59, 1777 - 1804.

Altinkilic, Oya, and Robert S. Hansen, 2000, Are There Economies of Scale in Underwriting Fees? Evidence of Rising External Financing Costs, Review of Financial Studies 13, 191-218.

Altman, Edward I., Brooks Brady, Andrea Resti, and Andrea Sironi, 2002, The Link between Default and Recovery Rates: Implications for Credit Risk Models and Procyclicity, Unpublished working paper.

Andrade, Gregor, and Steven N. Kaplan, 1998, How Costly Is Financial (Not Economic) Distress? Evidence from Highly Leveraged Transactions That Became Distressed, Journal of Finance 53, $1443-93$.

Bansal, Ravi, and Amir Yaron, 2004, Risks for the Long Run: A Potential Resolution of Asset Pricing Puzzles, Journal of Finance 59, 1481-1509.

Berk, Jonathan B., Richard C. Green, and Vasant Naik, 1999, Optimal Investment, Growth Options, and Security Returns, Journal of Finance 54, 1553-1607. 
Bernanke, Ben S., and Mark L. Gertler, 1995, Inside the Black Box: The Credit Channel of Monetary Policy Transmission, Journal of Economic Perspectives 9, 27-48.

Bertola, Giuseppe, and Ricardo J. Caballero, 1994, Cross-Sectional Efficiency and Labour Hoarding in a Matching Model of Unemployment, Review of Economic Studies 61, 435-56.

Bhamra, Harjoat S., Lars A. Kuehn, and Ilya A. Strebulaev, 2008, The Levered Equity Risk Premium and Credits Spreads: A Unified Approach, Unpublished working paper.

Bonomo, Marco, and Rene Garcia, 1996, Consumption and equilibrium asset pricing: An empirical assessment, Journal of Empirical Finance 3, 239-265.

Calvet, Laurent E., and Adlai J. Fisher, 2007, Multifrequency News and Stock Returns, Journal of Financial Economics 86, 178-212.

Calvet, Laurent E., and Adlai J. Fisher, 2008, Multifrequency Jump-Diffusions: An Equilibrium Approach, Journal of Mathematical Economics 44, 207-226.

Campbell, John Y., and John H. Cochrane, 1999, By Force of Habit: A Consumption-Based Explanation of Aggregate Stock Market Behavior, Journal of Political Economy 107, 205-251.

Campbell, John Y., and Robert J. Shiller, 1988, The Dividend-Price Ratio and Expectations of Future Dividends and Discount Factors, Review of Financial Studies 1, 195-228.

Carpenter, Robert E., Steven M. Fazzari, and Bruce C. Petersen, 1994, Inventory Investment, InternalFinance Fluctuation, and the Business Cycle, Brookings Papers on Economic Activity 25, 75-138.

Cecchetti, Stephen G., Pok-sang Lam, and Nelson C. Mark, 1993, The Equity Premium and the Risk-Free Rate: Matching the Moments, Journal of Monetary Economics 31, 21-45.

Chen, Hui, 2008, Macroeconomic Conditions and the Puzzles of Credit Spreads and Capital Structure, Unpublished working paper.

Chen, Long, Pierre Collin-Dufresne, and Robert S. Goldstein, 2008, On the Relation Between Credit Spread Puzzles and the Equity Premium Puzzle, Review of Financial Studies, forthcoming.

Covas, Francisco, and Wouter J. Den Haan, 2007, The Role of Debt and Equity Finance over the Business Cycle, Unpublished working paper.

Das, Sanjiv R., Darrell J. Duffie, Nikunj Kapadia, and Leandro Saita, 2008, Common Failings: How Corporate Defaults Are Correlated, Journal of Finance 62, 93-117.

Duffie, Darrell, and Larry G. Epstein, 1992, Stochastic Differential Utility, Econometrica 60, 353-94.

Duffie, J. Darrell, Leandro Saita, and Ke Wang, 2007, Multi-Period Corporate Default Prediction with Stochastic Covariates, Journal of Financial Economics 83, 635-665.

Epstein, Larry G., and Stanley E. Zin, 1989, Substitution, Risk Aversion, and the Temporal Behavior of Consumption and Asset Returns: A Theoretical Framework, Econometrica 57, 937-69.

Fazzari, Steven M., R. Glenn Hubbard, and Bruce C. Petersen, 1988, Financing Constraints and Corporate Investment, Brookings Papers on Economic Activity 19, 141-206. 
Fischer, Edwin O., Robert Heinkel, and Josef Zechner, 1989, Dynamic Capital Structure Choice: Theory and Tests, Journal of Finance 44, 19-40.

Gertler, Mark, and Simon Gilchrist, 1994, Monetary Policy, Business Cycles, and the Behavior of Small Manufacturing Firms, Quarterly Journal of Economics 109, 309-40.

Gertler, Mark L., and Simon Gilchrist, 1993, The Role of Credit Market Imperfections in the Monetary Transmission Mechanism: Arguments and Evidence, The Scandinavian Journal of Economics 95, 43-64.

Goldstein, Robert, Nengjiu Ju, and Hayne Leland, 2001, An EBIT-Based Model of Dynamic Capital Structure, Journal of Business 74, 483-512.

Graham, John R., 2000, How Big Are the Tax Benefits of Debt?, Journal of Finance 55, 1901-41.

Guo, Xin, 2001, An Explicit Solution to an Optimal Stopping Problem with Regime Switching, Journal of Applied Probability 38, 464-481.

Hackbarth, Dirk, Jianjun Miao, and Erwan Morellec, 2006, Capital Structure, Credit Risk and Macroeconomic Conditions, Journal of Financial Economics 82, 519-550.

Hamilton, James D., 1989, A New Approach to the Economic Analysis of Nonstationary Time Series and the Business Cycle, Econometrica 57, 357-84.

Hansen, Lars Peter, John Heaton, and Nan Li, 2006, Consumption Strikes Back?: Measuring Long Run Risk, Unpublished working paper.

Hennessy, Christoper A., and Toni M. Whited, 2005, Debt Dynamics, Journal of Finance 60, 1129-1165.

Hennessy, Christoper A., and Toni M. Whited, 2007, How Costly Is External Financing? Evidence from a Structural Estimation, Journal of Finance 62, 1705 - 1745.

Jobert, Arnaud, and L. C. Rogers, 2006, Option pricing with Markov-modulated dividends, SIAM Journal for Control and Optimization 44, 2063-2078.

Ju, Nengjiu, Robert Parrino, Allen M. Poteshman, and Michael S. Weisbach, 2005, Horses and Rabbits? Trade-Off Theory and Optimal Capital Structure, Journal of Financial and Quantitative Analysis 40, 259-281.

Kandel, Shmuel, and Robert F. Stambaugh, 1991, Asset Returns and Intertemporal Preferences, Journal of Monetary Economics 27, 39-71.

Kiyotaki, Nobuhiro, and John Moore, 1997, Credit Cycles, Journal of Political Economy 105, 211-48.

Korajczyk, Robert A., and Amnon Levy, 2003, Capital Structure Choice: Macroeconomic Conditions and Financial Constraints, Journal of Financial Economics 68, 75-109.

Korteweg, Arthur, 2008, The Net Benefits to Leverage, Unpublished working paper.

Kreps, David M, and Evan L Porteus, 1978, Temporal Resolution of Uncertainty and Dynamic Choice Theory, Econometrica 46, 185-200. 
Leary, Mark T., and Michael R.. Roberts, 2005, Do Firms Rebalance Their Capital Structures?, Journal of Finance 60, 2575-2619.

Leland, Hayne E., 1994, Corporate Debt Value, Bond Covenants, and Optimal Capital Structure, Journal of Finance 49, 1213-52.

Lemmon, Michael L., Michael R. Roberts, and Jaime F. Zender, 2008, Back to the Beginning: Persistence and the Cross-Section of Corporate Capital Structure, Journal of Finance 63, 1575-1608.

Lucas, Robert E. B., 1978, Asset Prices in an Exchange Economy, Econometrica 46, 1429-1446.

Merton, Robert C., 1974, On the Pricing of Corporate Debt: The Risk Structure of Interest Rates, Journal of Finance 29, 449-70.

Morellec, Erwan, 2004, Can Managerial Discretion Explain Observed Leverage Ratios?, Review of Financial Studies 17, 257-294.

Schaefer, Stephen M., and Ilya A. Strebulaev, 2008, Structural Models of Credit Risk are Useful: Evidence from Hedge Ratios on Corporate Bonds, Journal of Financial Economics, forthcoming.

Schroder, Mark, and Costis Skiadas, 1999, Optimal Consumption and Portfolio Selection with Stochastic Differential Utility, Journal of Economic Theory 89, 68-126.

Strebulaev, Ilya, 2007, Do Tests of Capital Structure Theory Mean What They Say?, Journal of Finance $62,1747-1787$.

Thorburn, Karin S., 2000, Bankruptcy Auctions: Costs, Debt Recovery, and Firm Survival, Journal of Financial Economics 58, 337-68.

Weil, Philippe, 1990, Nonexpected Utility in Macroeconomics, Quarterly Journal of Economics 105, 29-42.

Welch, Ivo, 2004, Capital Structure and Stock Returns, Journal of Political Economy 112, 106-131.

Whited, Toni M., and Guojun Wu, 2006, Financial Constraints Risk, Review of Financial Studies 19, 531559 .

Whitelaw, Robert F., 2000, Stock Market Risk and Return: An Equilibrium Approach, Review of Financial Studies 13, 521-47.

Zhang, Zhipeng, 2008, Recovery rates and Macroeconomic Conditions: The Role of Loan Covenants, Unpublished working paper. 
Figure 1: Financial Policy at Refinancing and Risk Aversion

This figure shows how the optimal default boundaries, coupons, refinancing boundaries, and leverage levels for each state change as a function of relative risk aversion, $\gamma$. Leverage is at the refinancing date. Default and refinancing boundaries are given for coupon levels normalized to one in each state.
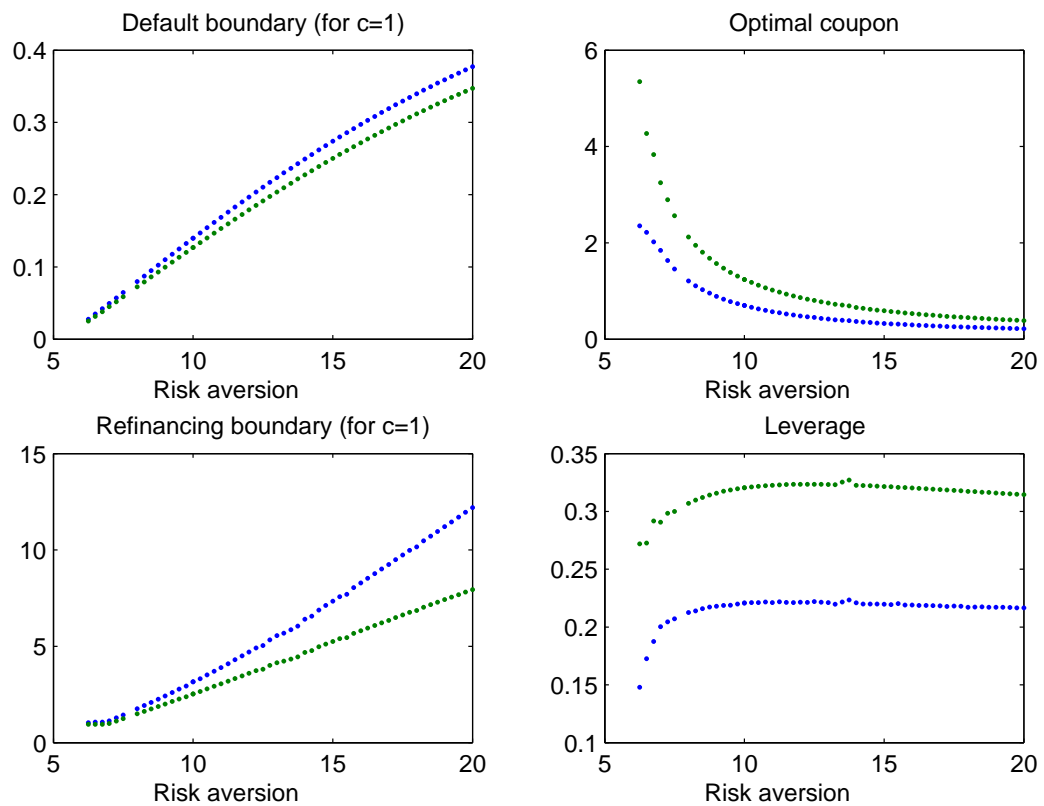
Figure 2: Financial Policy at Refinancing and Elasticity of Intertemporal Substitution

This figure shows how the optimal default boundaries, coupons, refinancing boundaries, and leverage levels for each state change as a function of elasticity of intertemporal substitution (EIS), $\psi$. Leverage is at the refinancing date. Default and refinancing boundaries are given for coupon levels normalized to one in each state.
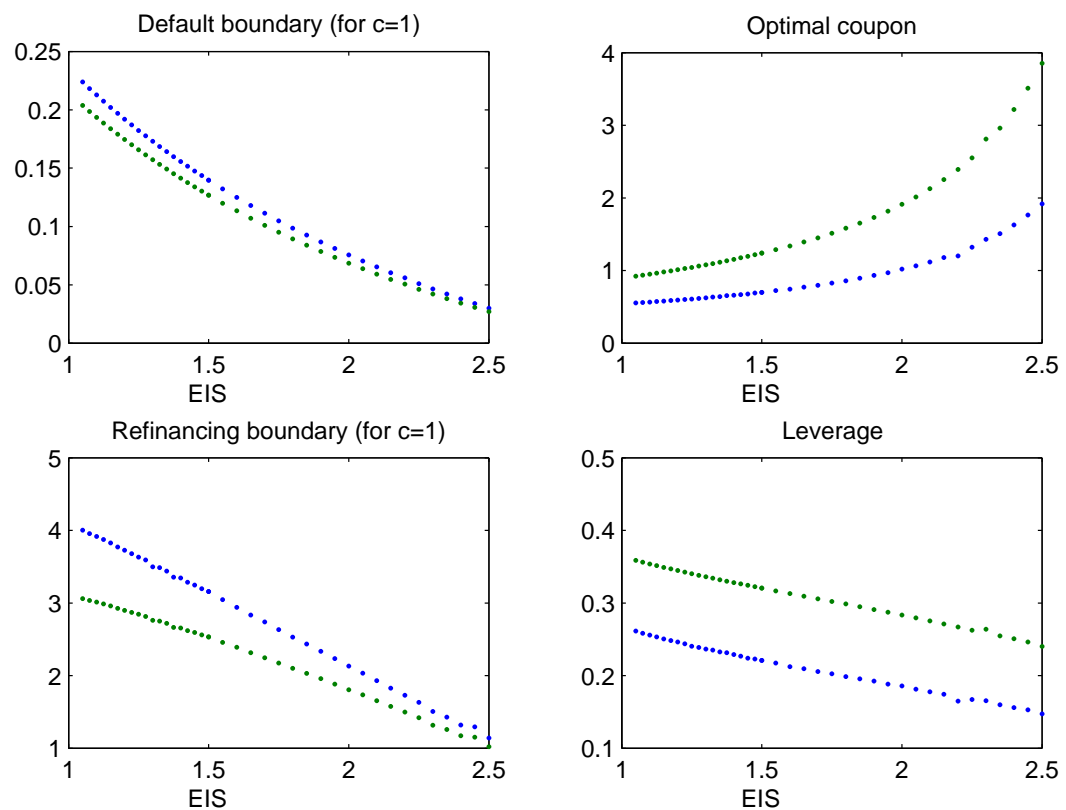
Figure 3: Financial Policy at Refinancing and Intertemporal Risk

This figure shows how the optimal default boundaries, coupons, refinancing boundaries, and leverage levels for each state change as a function of $p$, which is inversely proportional to intertemporal risk. Leverage is at the refinancing date. Default and refinancing boundaries are given for coupon levels normalized to one in each state.
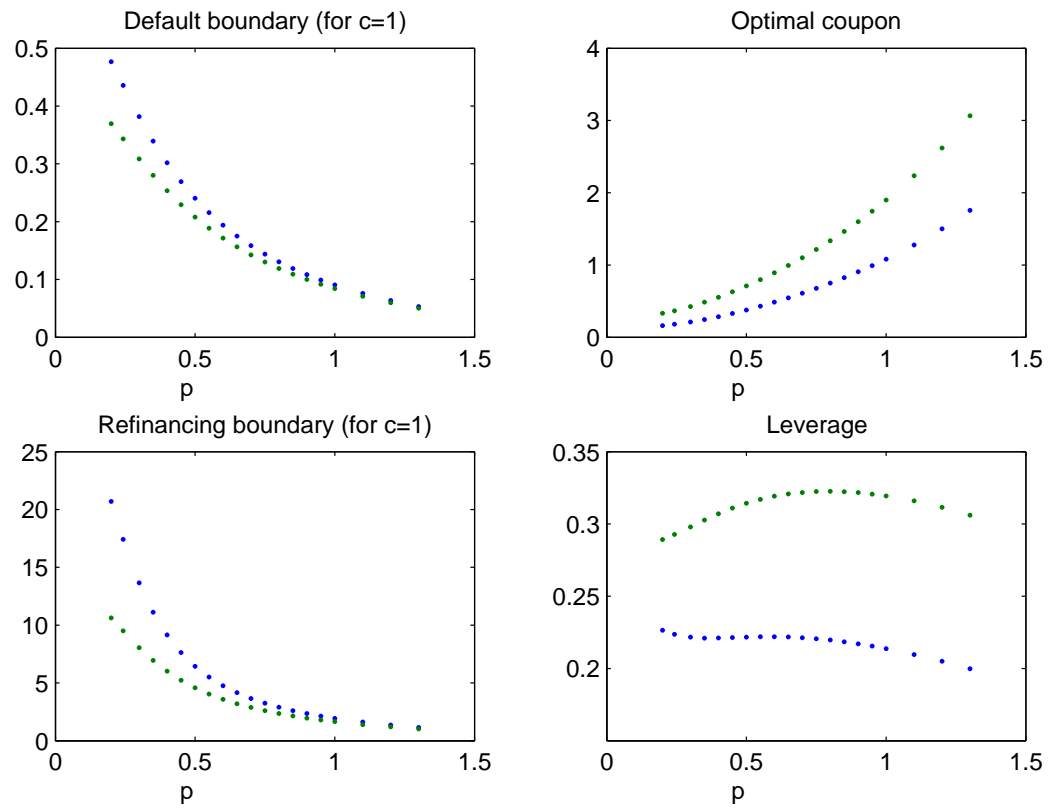
Figure 4: Financial Policy at Refinancing and Issuance Costs

This figure shows how the optimal default boundaries, coupons, refinancing boundaries, and leverage levels for each state change as a function of the issuance cost in state $1, \iota_{1}$. Leverage is at the refinancing date. Default and refinancing boundaries are given for coupon levels normalized to one in each state.
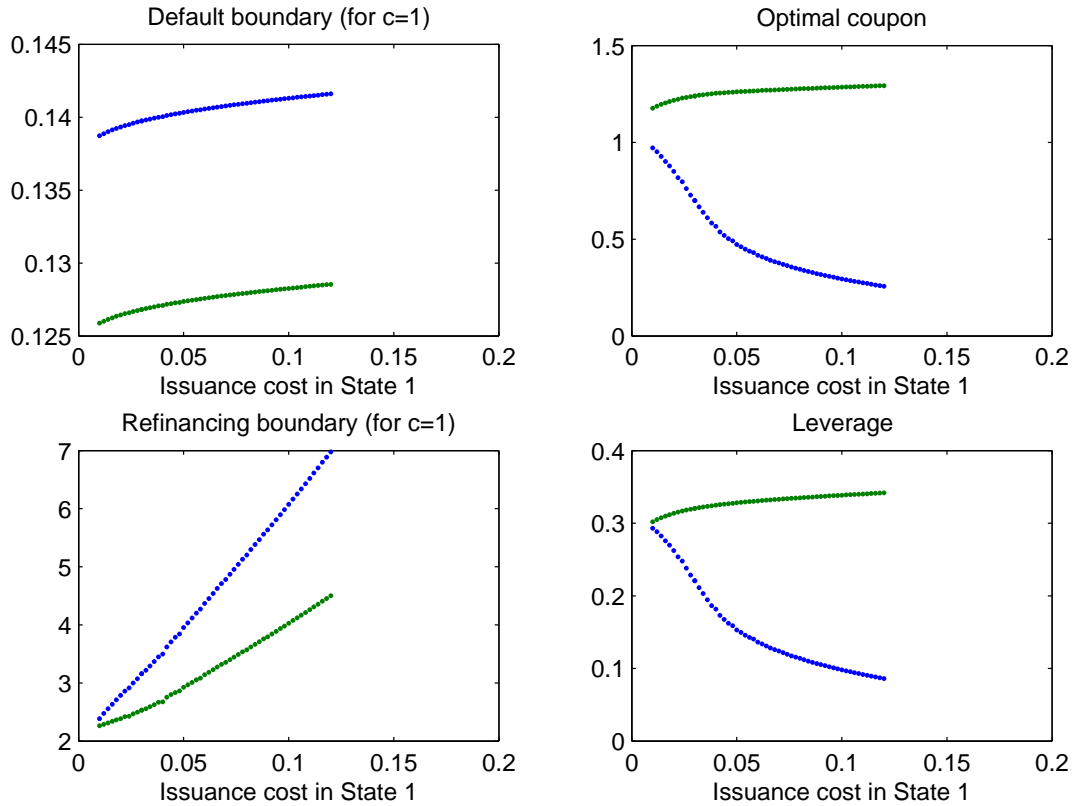
Figure 5: Time Variation of Aggregate Leverage

This figure shows the time variation of aggregate leverage for a typical economy. Aggregate leverage is the ratio of the sum of all debt to the sum of all firms' market value of assets. Grey areas show times when the economy in state 1 . The economy consists of 3,000 firms.

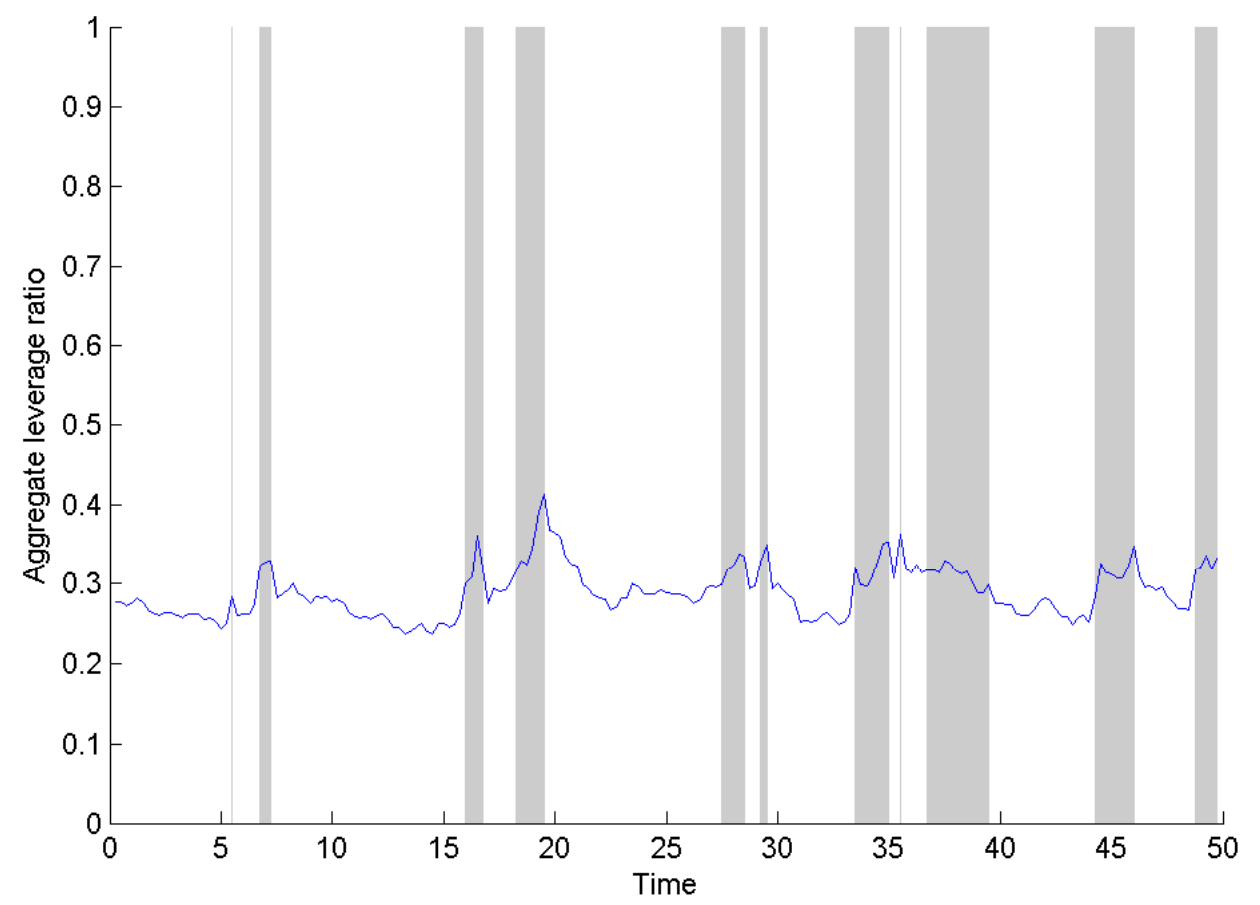


Figure 6: Leverage and Default Probability

This figure shows cumulative actual default probabilities over 5 (left plot) and 10 (right plot) years as function of leverage. For each leverage ratio 10,000 economies each containing 5,000 firms are simulated over 5 (10) years. Each plot shows 75th percentile, average, and $25 t h$ percentile default probabilities across all economies.
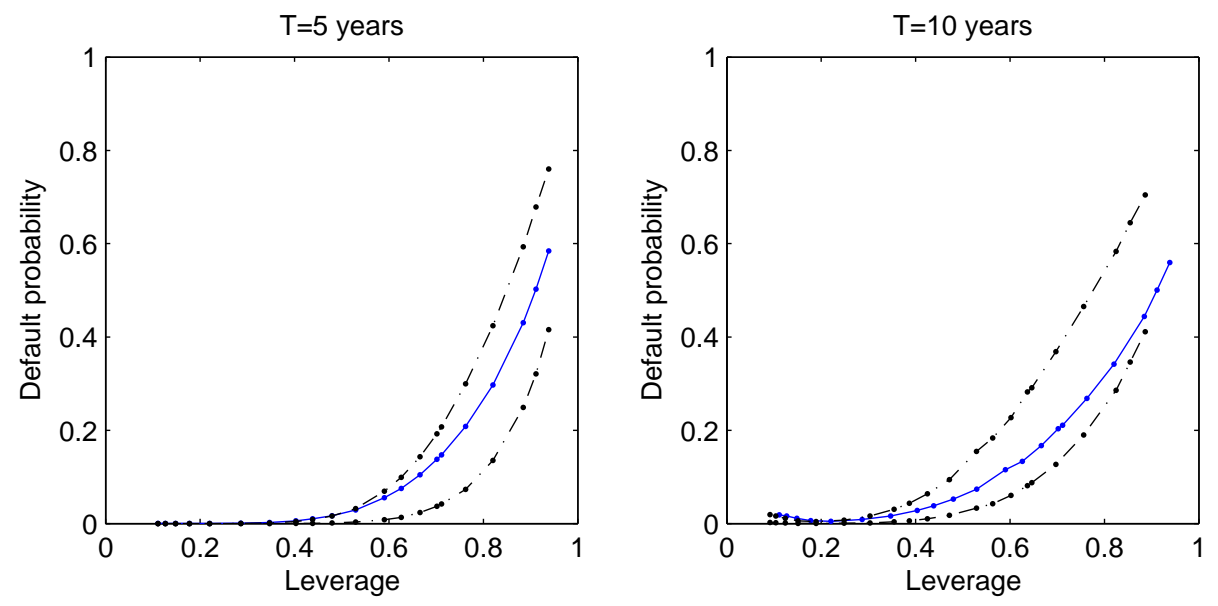


\section{Table I. Parameter Estimates}

This table reports the estimates of model parameters. To calibrate the model to the aggregate US economy, quarterly real non-durable plus service consumption expenditure from the Bureau of Economic Analysis and quarterly earnings data from Standard and Poor's, provided by Robert J. Shiller, are used. The personal consumption expenditure chain-type price index is used to deflate nominal earnings. The estimates of consumption growth rate and volatility, earnings growth rate and volatility, and correlation between earnings and consumption are obtained by maximum likelihood, annualized, and based on quarterly log growth rates for the period from 1947 to 2005. Panel A reports unconditional estimates. Panel B reports time-varying estimates for each state.

\begin{tabular}{lcc}
\hline \multicolumn{3}{c}{ Panel A: Unconditional Estimates } \\
\hline & Mean & Std. dev. \\
\hline Real consumption growth & 0.0333 & 0.0099 \\
Real earnings growth & 0.0343 & 0.1072 \\
\hline
\end{tabular}

\begin{tabular}{lccc}
\hline \multicolumn{4}{c}{ Panel B: Time-Varying Estimates } \\
\hline Parameter & Symbol & State 1 & State 2 \\
\hline Consumption growth rate & $g_{i}$ & 0.0141 & 0.0420 \\
Consumption growth volatility & $\sigma_{C, i}$ & 0.0114 & 0.0094 \\
Earnings growth rate & $\theta_{i}$ & -0.0401 & 0.0782 \\
Earnings growth volatility & $\sigma_{X, i}^{s}$ & 0.1334 & 0.0834 \\
Correlation & $\rho_{X C}$ & 0.1998 & 0.1998 \\
Actual long-run probabilities & $f_{i}$ & 0.3555 & 0.6445 \\
Actual convergence rate to long-run & $p$ & 0.7646 & 0.7646 \\
Annual discount rate & $\beta$ & $1 \%$ & $1 \%$ \\
Tax rate & $\eta$ & $15 \%$ & $15 \%$ \\
Bankruptcy costs & $1-\alpha_{i}$ & $30 \%$ & $10 \%$ \\
Idiosyncratic earnings growth volatility & $\sigma_{X}^{i d}$ & 0.2258 & 02258 \\
Relative risk aversion & $\gamma$ & 10 & 10 \\
Elasticity of intertemporal substitution & $\psi$ & 1.5 & 1.5 \\
\hline
\end{tabular}




\section{Table II. Optimal Financing Decisions at Refinancing}

This table reports optimal financing decisions in both states at a refinancing date. Default and refinancing boundaries are given for coupon levels normalized to one in each state. Leverage is the ratio of debt value to the sum of debt value and the market value of equity. Unconditional values are weighted average values across both states, where the weights are the long-run probabilities of being in each state.

\begin{tabular}{|c|c|c|c|c|c|c|}
\hline \multirow{2}{*}{$\begin{array}{l}\text { Optimal Financing } \\
\text { Choices }\end{array}$} & \multicolumn{3}{|c|}{ Static Financial Policy } & \multicolumn{3}{|c|}{ Dynamic Financial Policy } \\
\hline & Unconditional & State 1 & State 2 & Unconditional & State 1 & State 2 \\
\hline Leverage & 0.42 & 0.39 & 0.44 & 0.28 & 0.22 & 0.32 \\
\hline \multicolumn{7}{|l|}{ Default Boundary } \\
\hline State 1 Financing & 0.17 & 0.18 & 0.16 & 0.09 & 0.10 & 0.09 \\
\hline State 2 Financing & 0.23 & 0.24 & 0.22 & 0.16 & 0.17 & 0.16 \\
\hline \multicolumn{7}{|l|}{ Refinancing Boundary } \\
\hline State 1 Financing & & & & 1.92 & 2.19 & 1.76 \\
\hline State 2 Financing & & & & 3.40 & 3.89 & 3.13 \\
\hline
\end{tabular}




\section{Table III. Aggregate Dynamics of Financial Structure}

This table describes the aggregate dynamics of financial structure implied by the model. Leverage is the ratio of debt value to the sum of debt value and the market value of equity. Economy state is the fraction of time the economy spends in a particular state. Default and Refinancing are fractions of defaults and refinancings in each state of the total number of defaults and refinancings, respectively. The first two columns report values conditional on the current state of the economy. The last four columns report values conditional both on the current state and the previous refinancing state. One thousand data sets are generated, each containing 100 years of quarterly data for 3,000 firms. For each data set the statistics are first calculated for each year and then are averaged across years. Finally, they are averaged over data sets. 25th and $75 t h$ percentiles give the corresponding percentile values of the annual averages over the 1,000 data sets.

\begin{tabular}{lcccccc}
\hline \hline & State & State & \multicolumn{4}{c}{ Ref. State $\rightarrow$ Current State } \\
& 1 & 2 & $1 \rightarrow 1$ & $2 \rightarrow 1$ & $1 \rightarrow 2$ & $2 \rightarrow 2$ \\
\hline Leverage & & & & & & \\
Average & 0.44 & 0.38 & 0.41 & 0.46 & 0.36 & 0.39 \\
25th percentile & 0.42 & 0.36 & 0.38 & 0.42 & 0.34 & 0.36 \\
$\quad$ 75th percentile & 0.48 & 0.41 & 0.43 & 0.50 & 0.38 & 0.42 \\
Economy state & & & & & & \\
$\quad$ Average & 0.36 & 0.64 & 0.11 & 0.25 & 0.17 & 0.47 \\
25th percentile & 0.27 & 0.53 & 0.05 & 0.18 & 0.12 & 0.36 \\
75th percentile & 0.47 & 0.73 & 0.15 & 0.31 & 0.21 & 0.58 \\
Default & & & & & & \\
Average & 0.56 & 0.44 & 0.15 & 0.41 & 0.12 & 0.33 \\
25th percentile & 0.45 & 0.30 & 0.08 & 0.31 & 0.06 & 0.21 \\
75th percentile & 0.70 & 0.55 & 0.20 & 0.52 & 0.15 & 0.42 \\
Refinancing & & & & & & \\
Average & 0.16 & 0.84 & 0.07 & 0.10 & 0.33 & 0.51 \\
25th percentile & 0.09 & 0.79 & 0.02 & 0.06 & 0.23 & 0.38 \\
75th percentile & 0.21 & 0.91 & 0.09 & 0.13 & 0.41 & 0.64 \\
\hline \hline
\end{tabular}




\section{Table IV. Leverage and Default Probabilities}

This table reports the state-conditional cumulative default probabilities as a function of leverage ratios. Leverage is the ratio of debt value to the sum of debt value and the market value of equity. State $i \rightarrow$ State $j$ gives default probabilities for firm-years with current state of the economy $j$ and state at the previous refinancing $i$. $T$ is the number of years over which cumulative default probabilities are estimated. For each observation, ten thousand data sets are generated, each containing $T$ years of monthly data for 5,000 firms. Reported are average default probabilities and their standard deviations across all data sets.

\begin{tabular}{lcccccccc}
\hline \hline Leverage & State 1 $\rightarrow$ State 1 & \multicolumn{2}{c}{ State 2 $\rightarrow$ State 1} & \multicolumn{2}{c}{ State 1 $\rightarrow$ State 2 } & \multicolumn{2}{c}{ State 2 $\rightarrow$ State 2 } \\
& $T=5$ & $T=10$ & $T=5$ & $T=10$ & $T=5$ & $T=10$ & $T=5$ & $T=10$ \\
\hline $20 \%$ & 0.01 & 0.60 & 0.01 & 0.57 & 0.01 & 0.55 & 0.01 & 0.52 \\
& $(0.05)$ & $(1.51)$ & $(0.05)$ & $(1.42)$ & $(0.05)$ & $(1.41)$ & $(0.04)$ & $(1.34)$ \\
$30 \%$ & 0.10 & 1.76 & 0.09 & 1.71 & 0.08 & 1.58 & 0.08 & 1.62 \\
& $(0.39)$ & $(3.42)$ & $(0.44)$ & $(3.64)$ & $(0.35)$ & $(3.20)$ & $(0.36)$ & $(3.29)$ \\
$40 \%$ & 0.56 & 4.65 & 0.66 & 4.84 & 0.50 & 4.31 & 0.50 & 4.38 \\
& $(1.50)$ & $(6.81)$ & $(1.60)$ & $(7.18)$ & $(1.40)$ & $(6.36)$ & $(1.31)$ & $(6.47)$ \\
$50 \%$ & 2.16 & 9.58 & 2.32 & 9.90 & 1.98 & 9.41 & 1.91 & 9.36 \\
& $(4.03)$ & $(10.97)$ & $(4.07)$ & $(11.17)$ & $(3.77)$ & $(10.45)$ & $(3.57)$ & $(10.53)$ \\
$60 \%$ & 6.09 & 17.46 & 6.02 & 17.31 & 5.30 & 16.55 & 5.26 & 16.45 \\
& $(8.38)$ & $(15.70)$ & $(8.06)$ & $(15.24)$ & $(7.42)$ & $(14.60)$ & $(7.08)$ & $(14.00)$ \\
$70 \%$ & 13.58 & 28.05 & 13.51 & 27.87 & 12.55 & 27.17 & 12.47 & 27.17 \\
& $(13.66)$ & $(19.35)$ & $(13.38)$ & $(19.00)$ & $(12.45)$ & $(18.22)$ & $(12.24)$ & $(18.27)$ \\
$80 \%$ & 26.55 & 41.84 & 26.95 & 42.22 & 25.09 & 40.73 & 25.08 & 40.98 \\
& $(18.99)$ & $(21.55)$ & $(19.05)$ & $(21.59)$ & $(16.90)$ & $(19.83)$ & $(17.05)$ & $(20.03)$ \\
\hline \hline
\end{tabular}

